Revista

$A \circlearrowright O r$

das Ietras

\title{
O uso de ferramentas computacionais na elaboração do Vocabulário de Eulálio Motta: AntConc e FLEx
}

\author{
Computational tools used in the elaboration of the vocabulary of Eulálio Motta: \\ AntConc $e$ FLEx
}

\author{
Liliane Lemos Santana Barreiros* \\ Universidade Estadual de Feira de Santana \\ Feira de Santana, Bahia, Brasil
}

\begin{abstract}
Resumo: Com o crescente desenvolvimento das tecnologias computacionais, várias ferramentas estão disponíveis com o intuito de facilitar a construção de obras lexicográficas (dicionários, vocabulários, glossários etc.). Neste trabalho, objetiva-se descrever a funcionalidade e as etapas de aplicação de dois programas utilizados para a construção do Vocabulário do escritor baiano Eulálio de Miranda Motta: o AntConc, para a análise do corpus, e o Fieldworks Language Explorer (FLEx), para a organização do banco de dados e a edição dos verbetes. Adotou-se como base os princípios teórico-metodológicos da Lexicografia moderna (BIDERMAN, 1969; 1974; 1978; 1984; 2001; HAENSCH, 1982; BARBOSA, 2001, entre outros) e da Linguística de Corpus (BEBER SARDINHA, 2004; OTHERO; MENUZZI, 2005). Delimitou-se como corpus desta pesquisa 215 textos em prosa, escritos em vida ou publicados postumamente, sendo: 36 textos publicados na coluna Rabiscos do jornal Mundo Novo (1931 a 1932, Mundo Novo-BA); 17 textos publicados no jornal O Lidador (1933 a 1935, Jacobina-BA); 45 textos publicados no jornal O Serrinhense (1950 a 1951, Serrinha-BA); 24 textos publicados no jornal Gazeta do Povo (1960-1961, Feira de Santana-BA); 43 panfletos escritos de 1949 a 1983 (BARREIROS, P., 2015) e 50 causos que compõem Babia Humorística, escritos de 1933 a 1934 (BARREIROS, L., 2016). Entendese que essa seleção de 215 textos atende aos diversos suportes utilizados por Eulálio Motta para veiculação e divulgação de seus escritos, possibilitando inventariar o vocabulário usado pelo escritor durante um período de mais de 50 anos (de 1931 a 1983). O Vocabulário produzido é composto por 700 entradas, organizadas de A a Z, sendo 505 lexias simples, 61 lexias compostas e 134 lexias complexas (POTTIER, 1977), e tem como finalidade contribuir para a preservação de costumes e valores culturais do homem sertanejo, expresso no uso da língua.
\end{abstract}

Palavras-chave: Eulálio Motta. Vocabulário. AntConc. FLEx.

\begin{abstract}
With the increasing development of computational technologies, several tools are available to facilitate the construction of lexicographic works (dictionaries, vocabularies, glossaries, etc.). This paper aims to describe the functionality and stages of application of two softwares used to construct the Vocabulary of the bahian writer Eulálio de Miranda Motta: AntConc for the analysis of the corpus and the Fieldworks Language Explorer (FLEx) for the organization of the database and the editing of the entries. The theoreticalmethodological principles of modern Lexicography (BIDERMAN, 1969; 1974; 1978; 1984; 2001; HAENSCH, 1982; BARBOSA, 2001, among others) and a Linguistics Corpus (BEBER SARDINHA, 2004; OTHERO; MENUZZI, 2005). Delimited as the corpus of this research were 215 texts in prose, written in life or published
\end{abstract}

* Doutora em Língua e Cultura pela Universidade Federal da Bahia. Professora do Departamento de Letras e do PPGEL/MEL da Universidade Estadual de Feira de Santana. lilianebarreiros@uefs.br. 
posthumously, as follows: 36 texts published in the column Rabiscos of the newspaper Mundo Novo (1931 to 1932, Mundo Novo-BA); 17 texts published in the newspaper O Lidador (1933 to 1935, Jacobina-BA); 45 texts published in the newspaper O Serrinhense (1950 to 1951, Serrinha-BA); 24 texts published in the newspaper Gazeta do Povo (1960-1961, Feira de Santana-BA); 43 pamphlets written from 1949 to 1983 (BARREIROS, P., 2015) and 50 causos or anecdotes that composed the book Babia Humorística, written from 1933 to 1934 (BARREIROS, L., 2016). It is understood that this selection of 215 texts attends to the various supports used by Eulálio Motta to promote and disseminate his writings, making it possible to inventory the vocabulary used by the writer during a period of more than 50 years (1931 to 1983). The vocabulary produced is composed of 700 entries, organized from A to Z, being 505 simple lexias, 61 compound lexias and 134 complex lexias (POTTIER, 1977), and aims to contribute to the preservation of cultural customs and values of the country man, as expressed in the use of the language.

Keywords: Eulálio Motta. Vocabulary. AntConc. FLEx.

\section{INTRODUÇÃO}

O uso dos computadores e das técnicas quantitativas para análise da língua portuguesa iniciou na década de 1960. Neste período, grupos de pesquisadores do Brasil, Estados Unidos e França trabalharam simultaneamente, conforme seus interesses, em três linhas: "1) fins literários e/ou estilísticos; 2) fins linguísticos e 3) informáticos" (BIDERMAN, 1978, p. 64). Até então, as pesquisas em torno da língua, geralmente, eram voltadas para o ensino, e o corpus era coletado, registrado em fichas e analisado manualmente. Uma tarefa muito difícil, lenta e de alto custo.

Neste contexto, destaca-se um trabalho pioneiro para a lexicografia brasileira, a tese de doutoramento de Maria Tereza Camargo Biderman, intitulada Análise Computacional de Fernando Pessoa (Ensaio de Estatística Léxica), defendida em 1969, na Universidade de São Paulo - USP. Nos primórdios das discussões, Biderman utilizou o computador na tabulação de dados léxicos, com vistas a uma análise estilística da obra poética de Fernando Pessoa. Dentro do mesmo domínio de conhecimento, em 1974, na USP, ela defendeu a tese de livre-docência $A$ Categoria do Gênero, na qual manipulou dados léxicos dos dicionários de frequência das línguas românicas, confrontando os tipos de gênero que existem nas cinco línguas (português, espanhol, francês, italiano e romeno).

A partir de então, com a popularização dos computadores pessoais, no início da década de 1980, aliado ao desenvolvimento da Linguística de Corpus, as pesquisas passaram a priorizar a descrição da língua e a análise de grande quantidade de dados tornou-se mais confiável. Além disso, possibilitou testar as hipóteses, confrontando a teoria com os dados empíricos da língua. De acordo com Berber Sardinha (2004):

A Linguística de Corpus ocupa-se da coleta e da exploração de corpora, ou conjuntos de dados linguísticos textuais coletados criteriosamente, com o propósito de servirem para a pesquisa de uma língua ou variedade linguística. Como tal, dedica-se à exploração da linguagem por meio de evidências empíricas, extraídas por computador (BERBER SARDINHA, 2004, p. 3). 
A Linguística de Corpus está atrelada à Linguística Computacional que, por sua vez, é uma área da ciência linguística voltada para o tratamento computacional da linguagem e das línguas naturais (OTHERO; MENUZZI, 2005, p. 25). Este campo do saber estabelece uma interseção entre os conhecimentos desenvolvidos pela engenharia da computação e as diferentes pesquisas tradicionalmente conhecidas em Linguística teórica e aplicada. Como resultado dessa parceria entre os linguistas e os engenheiros da computação, destaca-se a criação de softwares para o estudo de determinados fenômenos linguísticos e a sua ocorrência, a partir da constituição de grandes bancos de dados eletrônicos.

Para Biderman (1984), "o advento do computador constituiu uma verdadeira revolução dentro da ciência da informática e da lexicografia em particular”" (BIDERMAN, 1984, p. 17). Na segunda edição do livro Teoria linguística, ela destaca que no domínio filológico e literário as técnicas computacionais também foram benéficas (BIDERMAN, 2001, p. 87). Contudo, "a Lexicografia e a Terminologia são indubitavelmente as áreas do conhecimento linguístico que mais se beneficiaram com as informações propiciadas pelos corpora de língua escrita e falada e pelas ferramentas computacionais" (BIDERMAN, 2001, p. 92).

Os benefícios alcançados certamente são inúmeros. Além da velocidade na execução das atividades e da ampla capacidade de armazenamento de dados, as novas tecnologias permitem ao lexicógrafo coletar, selecionar, registrar, analisar, aperfeiçoar, recuperar os dados e gerar documentos publicáveis com baixo custo. Ressalta-se que essas vantagens não se limitam apenas na execução das etapas de elaboração de grandes dicionários, mas favorecem ao progresso das pesquisas linguísticas de diversas áreas, atrelando produtividade, com qualidade e acessibilidade.

Para a elaboração do Vocabulário de Eulálio Motta (BARREIROS, L., 2017), o primeiro passo foi delimitar o corpus. A respeito do conceito de corpus, Berber Sardinha (2004) analisa algumas definições e destaca a elaborada por Sanchez-Cantos, em 1996, segundo a qual corpus é:

Um conjunto de dados linguísticos (pertencentes ao uso oral ou escrito da língua, ou a ambos), sistematizados segundo determinados critérios, suficientemente extensos em amplitude e profundidade, de maneira que sejam representativos da totalidade do uso linguístico ou de algum de seus âmbitos, dispostos de tal modo que possam ser processados por computador, com a finalidade de propiciar resultados vários e úteis para a descrição e análise (BERBER SARDINHA, 2004, p. 18).

Berber Sardinha (2004, p. 19-20) assinala ainda quatro pré-requisitos para a formação de um corpus eletrônico: 1) a origem - o corpus deve ser composto de textos autênticos, em linguagem natural; 2) a autenticidade - escritos por falantes nativos; 3) o conteúdo - deve obedecer a critérios estabelecidos pelo criador de modo que o corpus coletado corresponda às características desejadas; e 4) a representatividade - deve ter uma extensão representativa. 
Neste sentido, delimitou-se como corpus para a construção do Vocabulário de Eulálio Motta as publicações de textos em prosa, escritos em vida ou publicados postumamente, sendo: 36 textos publicados na coluna Rabiscos do jornal Mundo Novo (1931 a 1932); 17 textos publicados no jornal O Lidador (1933 a 1935); 45 textos publicados no jornal $O$ Serrinhense (1950 a 1951); 24 textos publicados no jornal Gareta do Povo (1960-1961); 43 panfletos escritos de 1949 a 1983 (BARREIROS, P., 2015) e 50 causos que compõem Bahia Humorística, escritos de 1933 a 1934 (BARREIROS, L., 2016). Entende-se que essa seleção de 215 textos atende aos diversos suportes utilizados por Eulálio Motta para veiculação e divulgação de seus escritos, possibilitando inventariar o vocabulário usado pelo escritor durante um período de mais de 50 anos (de 1931 a 1983). Trata-se de textos autênticos, selecionados criteriosamente, que perfazem um total de 85.845 tokens (número total de palavras do corpus) e 12.861 types (número de palavras do corpus contadas apenas uma vez), cumprindo assim o requisito de representatividade.

Após a etapa de seleção dos textos, passou-se à etapa de edição e, em seguida, à compilação propriamente dita. Os textos foram salvos em arquivos separados em formato Word, PDF e TXT e nomeados conforme o código estabelecido por L. Barreiros (2017). Esta nomeação seguiu um padrão para facilitar a recuperação posterior de cada texto.

Atualmente, com o crescente desenvolvimento das tecnologias computacionais, várias ferramentas estão disponíveis com o intuito de facilitar a construção de trabalhos lexicográficos. Após análise e testes com alguns softwares que poderiam auxiliar na construção do Vocabulário de Eulálio Motta, foram escolhidos dois programas: o AntConc, para a análise do corpus, e o Fieldworks Language Explorer (FLEx), para a edição e a organização dos verbetes, pois demonstraram eficiência, principalmente, em virtude da flexibilidade, visto que se adaptam às necessidades específicas de cada produção. A seguir, descrevem-se a funcionalidade e as etapas de aplicação de cada um dos programas adotados.

\section{ANTCONC: SOFTWARE PARA ANÁLISE DE CORPUS}

O AntConc é um software gratuito para análise de corpus, que foi desenvolvido pelo pesquisador Laurence Anthony da Faculdade de Ciências e Engenharia da Universidade de Waseda no Japão. Trata-se de uma ferramenta multiplataforma, executável em versões para o Windows, Linux e Macintocsh. Seu arquivo tem aproximadamente $4 \mathrm{Mb}$, por isso é considerado leve e dispensa a necessidade de instalação, o que torna a utilização mais fácil mesmo para usuários iniciantes. Optou-se pelo modelo AntConc 3.4.4 ${ }^{1}$, a última versão para o Windows, que dispõe em sua homepage (cf. Figura 1) de um canal de suporte com manual, tutoriais em vídeo e grupos de discussão traduzidos do japonês para o inglês.

1 Cf. Anthony (2014). Download disponível em: http://www.laurenceanthony.net/software/antconc/. Acesso em: 6 abr. 2017. 


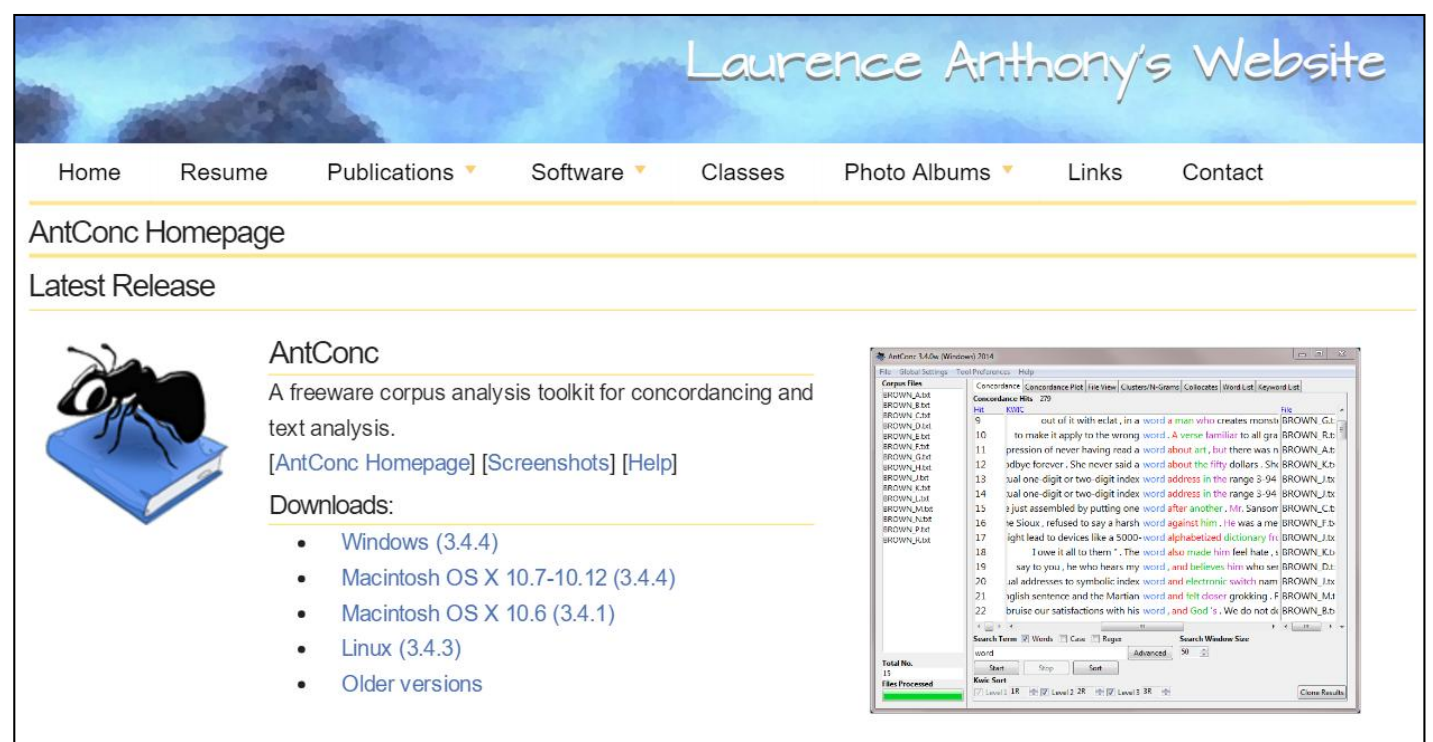

Figura 1 - Homepage do AntConc

Fonte: Anthony (2014).

A interface do AntConc é bem simples e, na mesma janela, é possível navegar por diferentes opções de análise, que permitem descobrir como uma palavra ocorre, o quanto ocorre, em que contextos e quais a acompanha, encontrar padrões e variáveis de uso na escrita e fazer levantamento terminológico. Sua praticidade de uso possibilita a extração de listas de palavras (Word List), listas de concordâncias (Concordance) e de palavras-chaves (KeyWord), além de gerar gráficos com os dados analisados. Estas ferramentas são de grande relevância para o linguista, em especial, para o lexicógrafo, pois fornece o conjunto das combinações e das colocações que a palavra pode ter em um determinado corpus. Biderman (1984) destaca que:

[...] as concordâncias de texto são um manancial riquíssimo para documentar e ilustrar usos semânticos e gramaticais e atestar o que está ocorrendo de fato na língua, quando se trata de um trabalho sobre Lexicografia contemporânea (BIDERMAN, 1984, p. 22).

Nesta perspectiva, o uso das ferramentas computacionais permite fazer uma avaliação prévia, de forma rápida e econômica, obtendo grande quantidade de resultados em pouco tempo. O que possibilita ao pesquisador ter evidências para provar uma hipótese sobre determinado aspecto linguístico.

Para iniciar o trabalho com o AntConc, foi necessário carregar os arquivos com o corpus em TXT pelo menu File ${ }^{2}$. Para converter os arquivos compilados, utilizou-se o programa AntFileConverter ${ }^{3}$, que é uma ferramenta freeware que converte arquivos de PDF

2 Todos os itens comentados ao longo do texto estarão destacados em vermelho nas imagens ilustrativas.

${ }^{3}$ Disponível em: <http://www.laurenceanthony.net/software/antfileconverter/>. Acesso em: 6 abr. 2017. 
e Word (DOCX) em texto simples para uso em ferramentas de corpus. O AntFileConverter está na mesma plataforma do AntConc e é indicado pelo programa. Além de ser rápido e de fácil manuseio, ele salva os arquivos em TXT direto na pasta de origem, otimizando a inserção dos mesmos no programa de análise. Essa tarefa é feita pela opção Open File(s), que permite abrir os arquivos individualmente, ou pela opção Open Dir, quando for carregar uma pasta completa. Os nomes e a quantidade dos arquivos selecionados aparecerão no quadro Corpus Files, à esquerda da tela, como se pode ver na Figura 2.

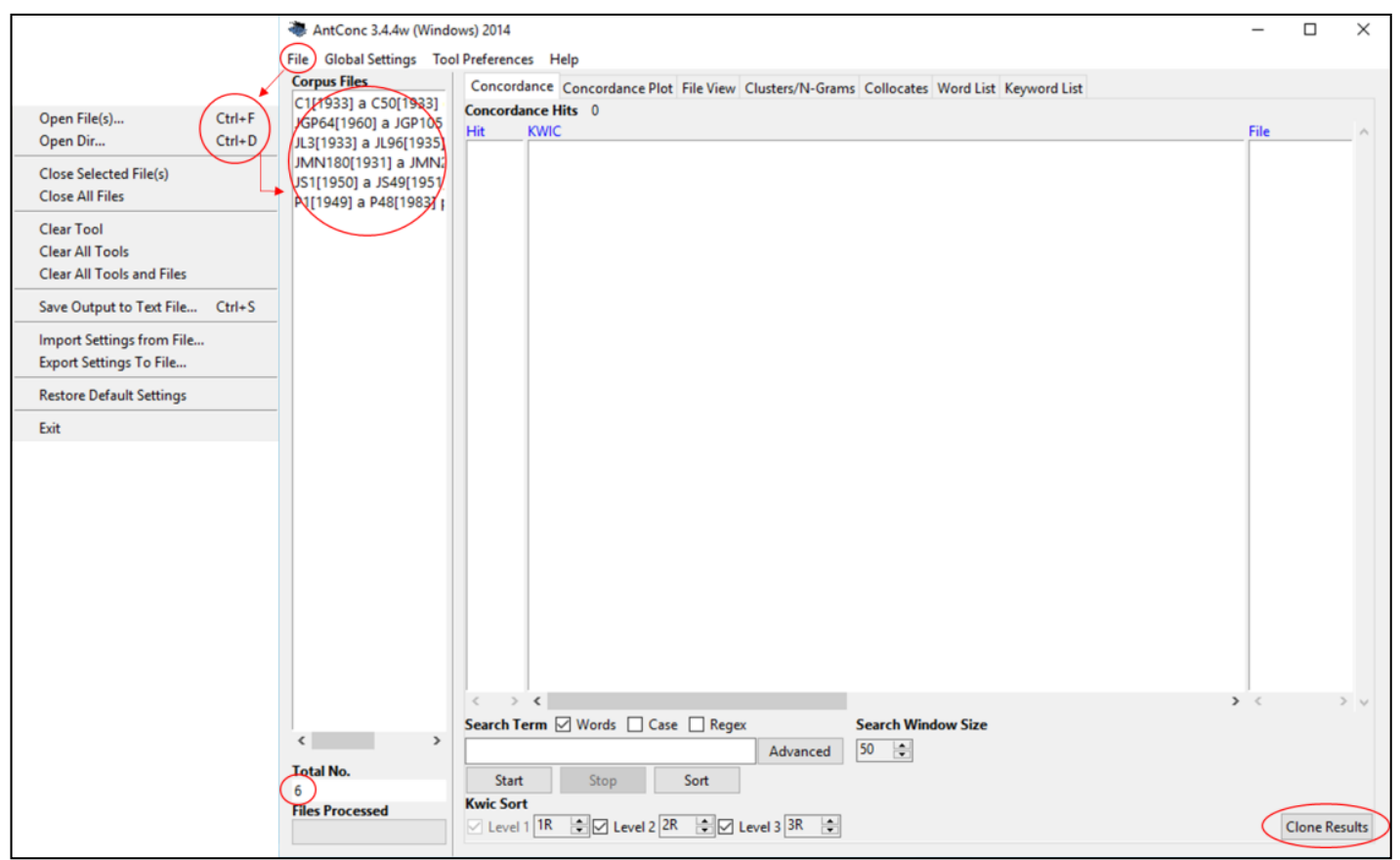

Figura 2 - Tela inicial do AntConc

Fonte: Elaborada pela pesquisadora.

Ainda no menu File, tem-se a opção de selecionar e excluir arquivos, salvar os resultados das análises realizadas, importar e exportar os dados e restaurar a configuração original.

O botão Clone Results, à direita, no final da tela, permite criar uma cópia dos resultados para que possam ser comparados, em janelas independentes. Essa função é importante, quando se tem interesse em confrontar o conjunto dos dados obtidos.

Antes de ativar qualquer função de análise no AntConc, é preciso configurar a língua no menu Global Settings (cf. Figura 3). Como o corpus está escrito em língua portuguesa, a melhor opção é Western Latin 1. Ainda no menu das configurações globais (Global Settings), é possível editar as opções de cor para realce na análise, a extensão do arquivo a ser aberto (TXT, html, xml ou ALL - todos esses formatos), o tipo e o tamanho da fonte. 


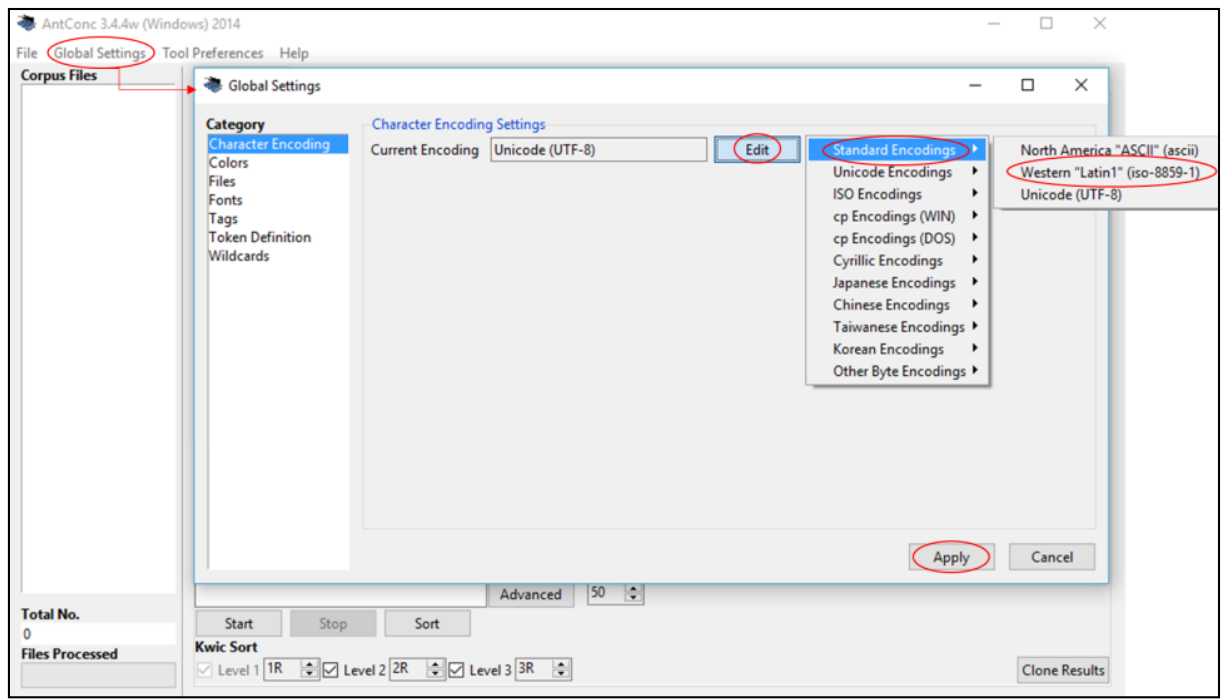

Figura 3 - Configuração do menu Global Settings do AntConc Fonte: Elaborada pela pesquisadora.

É importante lembrar também de configurar o menu Tool Preferences (cf. Figura 4). Nele, deve-se marcar no campo Other Options a caixa Treat all data as lowercase (tratar todos os dados como minúsculas) das categorias Clusters/N-Grams, Collocates, Word List e Keyword List. Caso contrário, o programa irá diferenciar as letras iniciais entre maiúsculas e minúsculas da mesma palavra, o que causará problemas de exaustividade nos resultados, gerando duas entradas. A depender do objetivo da análise e do tipo de corpus trabalhado, essa configuração torna-se desnecessária.

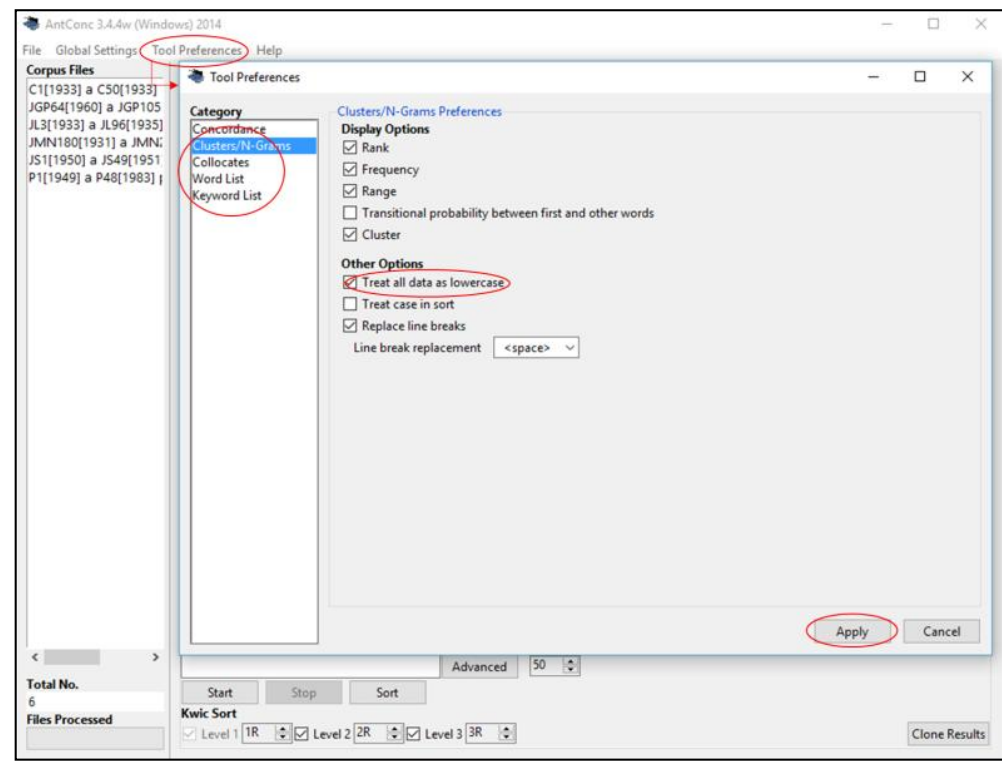

Figura 4 - Configuração do menu Tool Preferences do AntConc Fonte: Elaborada pela pesquisadora. 
A seguir, descrevem-se as principais ferramentas Concordance, Concordance Plot, File View, Clusters/N-Grams, Collocates, Word List e Keyword List e suas respectivas funções dentro do programa AntConc.

A primeira ferramenta do menu principal é Concordance - ela mostra os resultados da pesquisa em um formato 'KWIC' (KeyWord In Context), o que permite ver como palavras e frases são comumente usadas em um corpus. O resultado é apresentado em três colunas. Na primeira, quantificam-se as ocorrências, na segunda, têm-se as linhas de concordância com destaque para as palavras-chave no contexto, e na terceira, a identificação do arquivo em que se encontra. A título de exemplo, buscou-se no corpus de Eulálio Motta quantas vezes o escritor usou a forma $<$ Liota $>$ para se referir a si mesmo, como mostra a Figura 5:

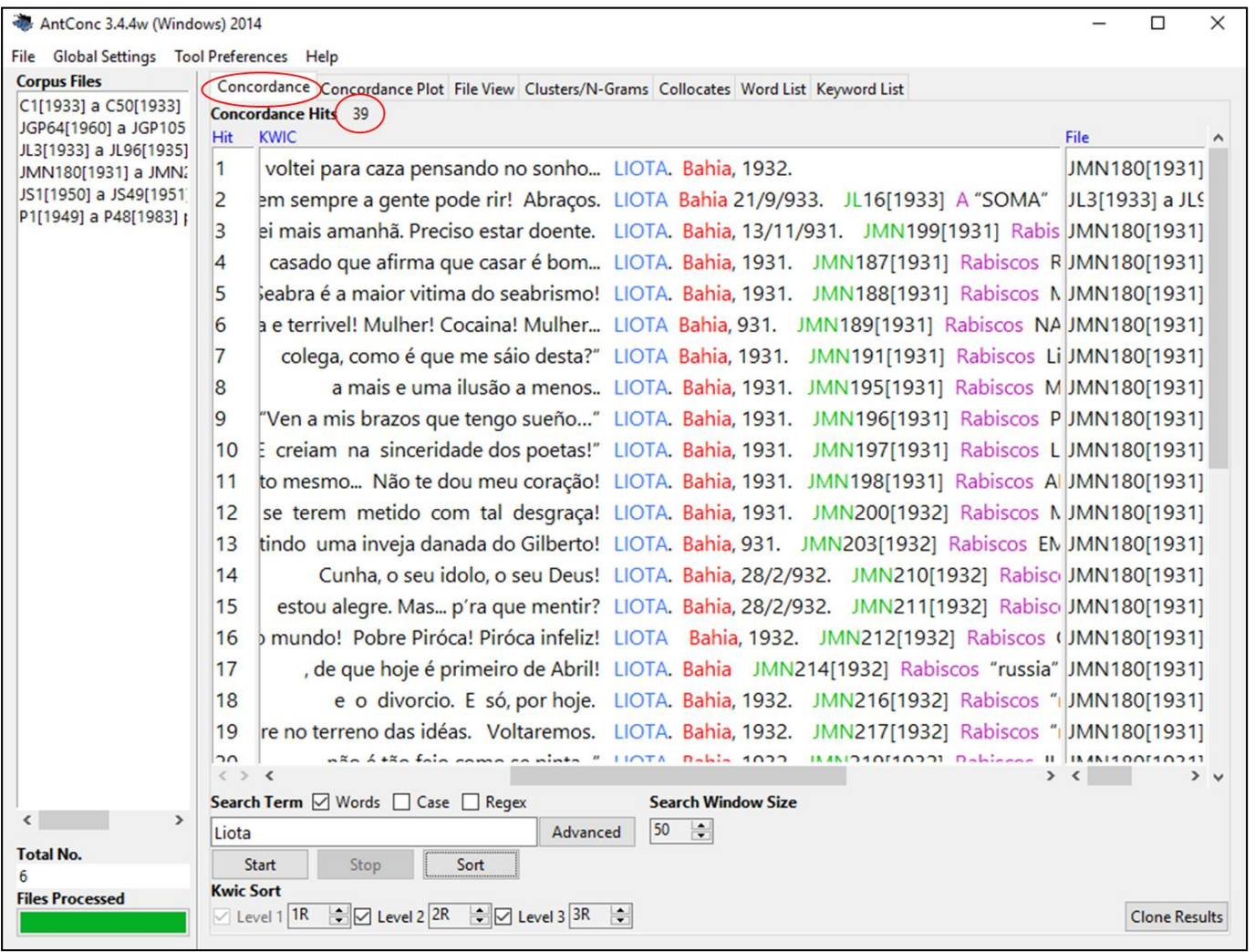

Figura 5 - Resultado da busca por $<$ Liota $>$ na ferramenta Concordance do AntConc Fonte: Elaborada pela pesquisadora.

Com a ferramenta Concordance foi possível localizar entre os 215 textos que compõe o corpus deste trabalho, 39 ocorrências de $<$ Liota $>$, nos respectivos contextos, com a indicação da data e do código de identificação do arquivo. Com os resultados, foi possível inferir que Eulálio Motta assinou como Liota no período de 1931, 1932 e 1933, apenas nos jornais Mundo Novo e O Lidador. A ampliação total do contexto e o acesso ao texto 
completo podem ser feitos clicando sobre a palavra-chave desejada ou acionando o recurso File View.

Concordance Plot é uma ferramenta de plotografia de concordância, que possibilita visualizar os resultados da pesquisa em forma de gráfico, semelhante a um código de barras, que mostra a distribuição, no arquivo em questão, da palavra que se está analisando. Ela permite ver quais os arquivos incluem a palavra pesquisada e onde aparecem no texto. O número de ocorrências e o comprimento de cada texto é mostrado à direita do gráfico. Este, por sua vez, pode ser ampliado ou reduzido usando o botão Plot Zoom. Para exemplificar, buscou-se por <Mundo Novo $>$ e o resultado apresentou ocorrências em todos os arquivos, como se vê na Figura 6:

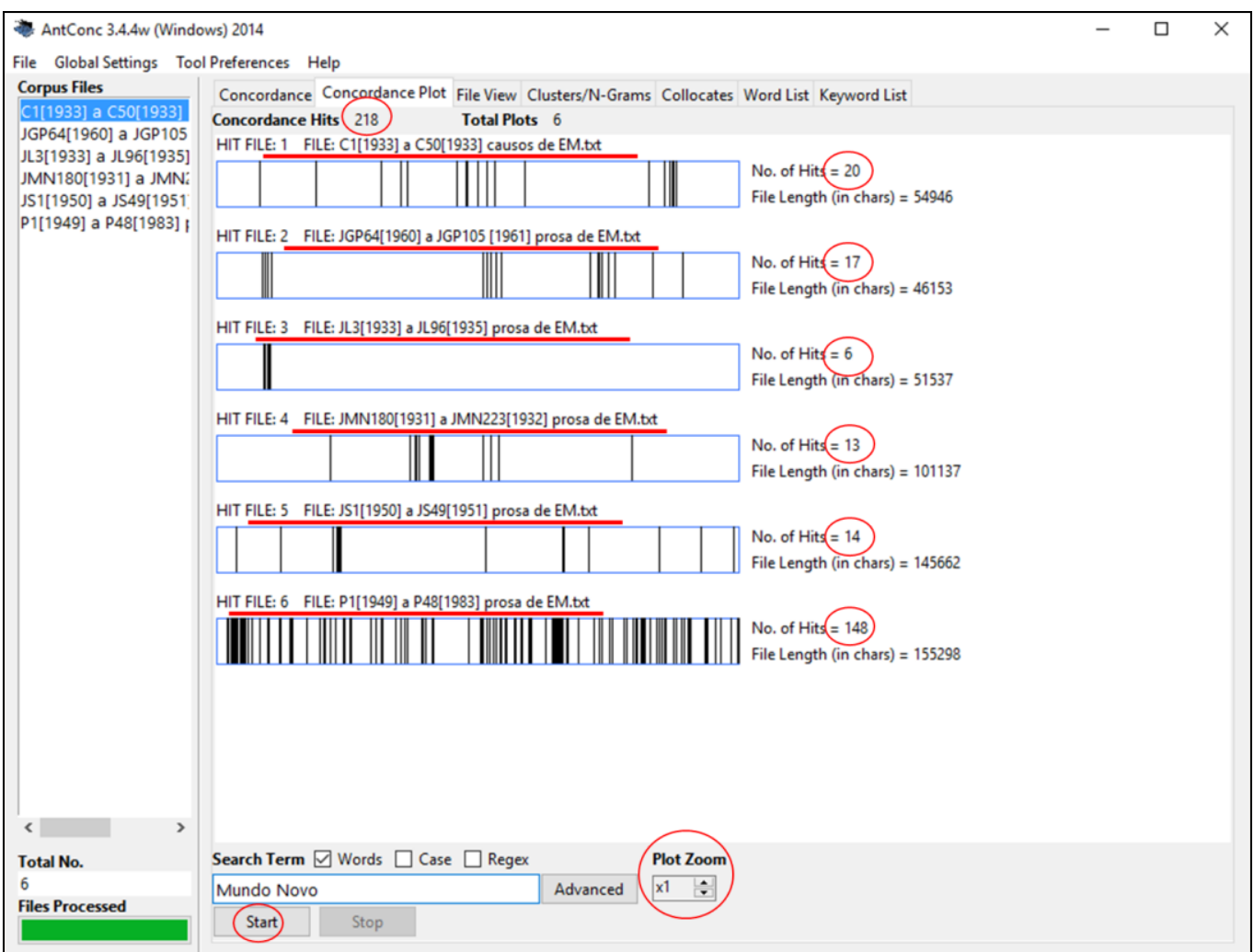

Figura 6 - Resultado da busca por $<$ Mundo Novo $>$ na ferramenta Concordance Plot do AntConc Fonte: Elaborada pela pesquisadora.

Com a ferramenta Concordance Plot, identificaram-se 218 ocorrências, sendo 6 no jornal O Lidador, 13 no jornal Mundo Novo, 14 no jornal O Serrinhense, 17 no jornal Gazeta do Povo, no 20 nos causos e 148 nos panfletos. Ao clicar em cada linha do gráfico, o usuário é remetido ao contexto da ocorrência. Com o auxílio da função Clusters/N-Grams, que será explicada mais adiante, identificaram-se 2 ocorrências grafadas com hífen $<$ MundoNovo $>$ e uma com acento circunflexo $<$ Mundo Nôvo $>$. 
A função File View mostra o texto bruto de arquivos individuais. Isto permite investigar com mais detalhes os resultados gerados pelas ferramentas Concordance e Concordance Plot, pois as diferentes ocorrências ficam sinalizadas. Neste caso, se uma palavra tiver sido especificada, os resultados serão destacados em todo o texto. Também é permitido alterar a busca. Com o botão Hit Location é possível saltar pelas ocorrências sem precisar percorrer todo o arquivo. A Figura 7, exemplifica a busca por $<$ Mundo Novo $>$ no arquivo dos panfletos (P1[1949] a P48[1983]), nos quais registram-se 148 ocorrências:

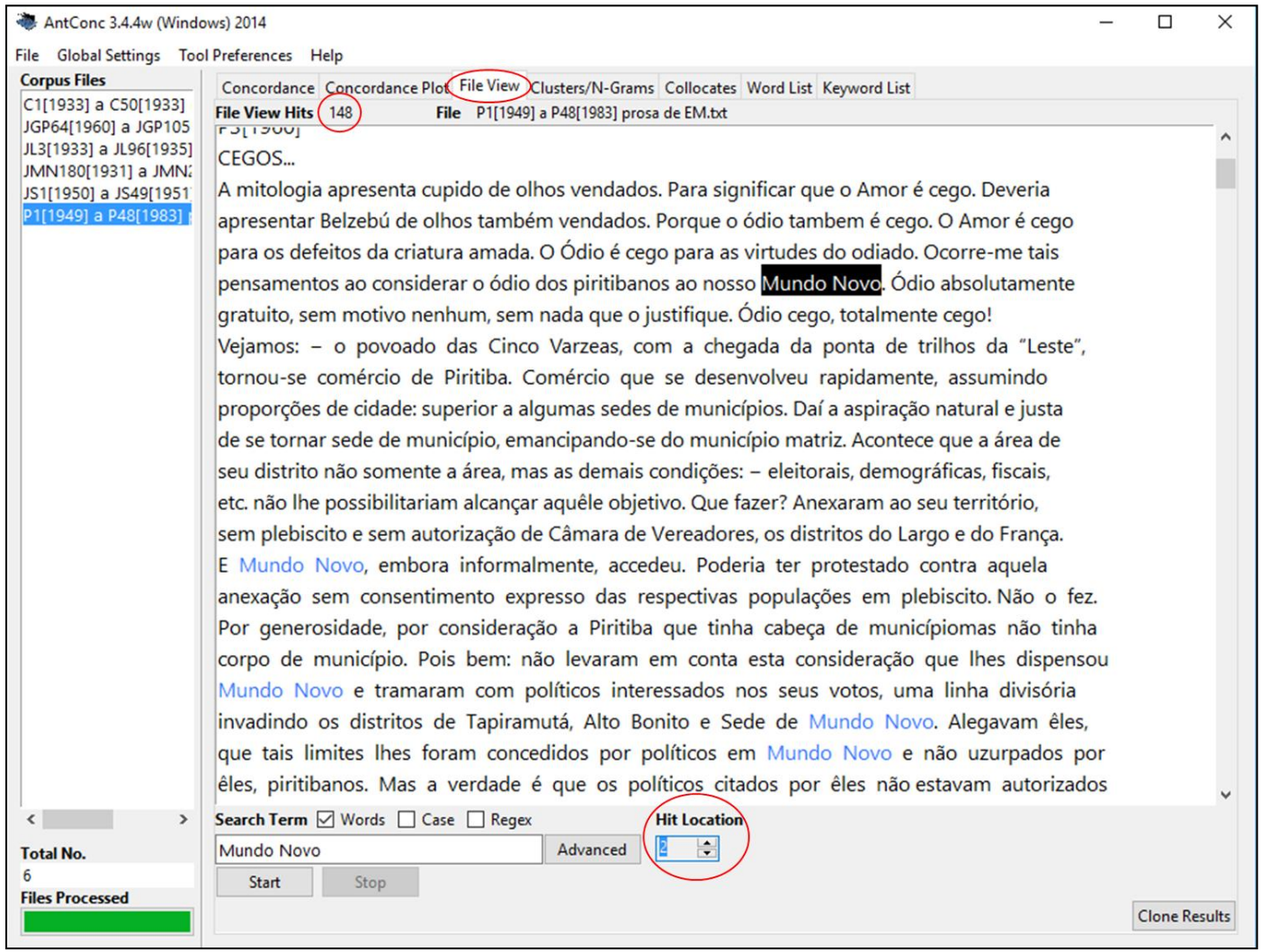

Figura 7 - Resultado da busca por $<$ Mundo Novo $>$ na ferramenta File View do AntConc Fonte: Elaborada pela pesquisadora.

A opção Clusters/N-Grams do modelo AntConc 3.4.4 acopla as funções Clusters e NGrams das versões anteriores. Esta ferramenta gera uma lista com o resultado da pesquisa, conforme a ordem escolhida (alfabética, de frequência, de probabilidade ou de terminações). A ordem dessas listas também pode ser invertida, ativando a opção Invert Order. Além dessas possibilidades, Clusters/N-Grams agrupa os resultados gerados na Concordance ou Concordance Plot com as palavras mais próximas à esquerda (On Left - busca padrão do programa) ou à direita do termo de pesquisa $(O n$ Right), de acordo com a opção assinalada. Pode-se selecionar o comprimento mínimo e máximo (número de palavras) em cada cluster e a frequência mínima de clusters exibidos, o que possibilita localizar 
expressões comuns em todo o corpus. Este procedimento é bem proveitoso quando se trabalha com o levantamento de lexias compostas e complexas.

$\mathrm{Na}$ Figura 8, realizou-se uma busca por <integralista>, utilizando a ferramenta Clusters/N-Grams, que gerou uma lista por ordem de frequência de 27 ocorrências, com a indicação das 4 palavras mais próximas à direita.

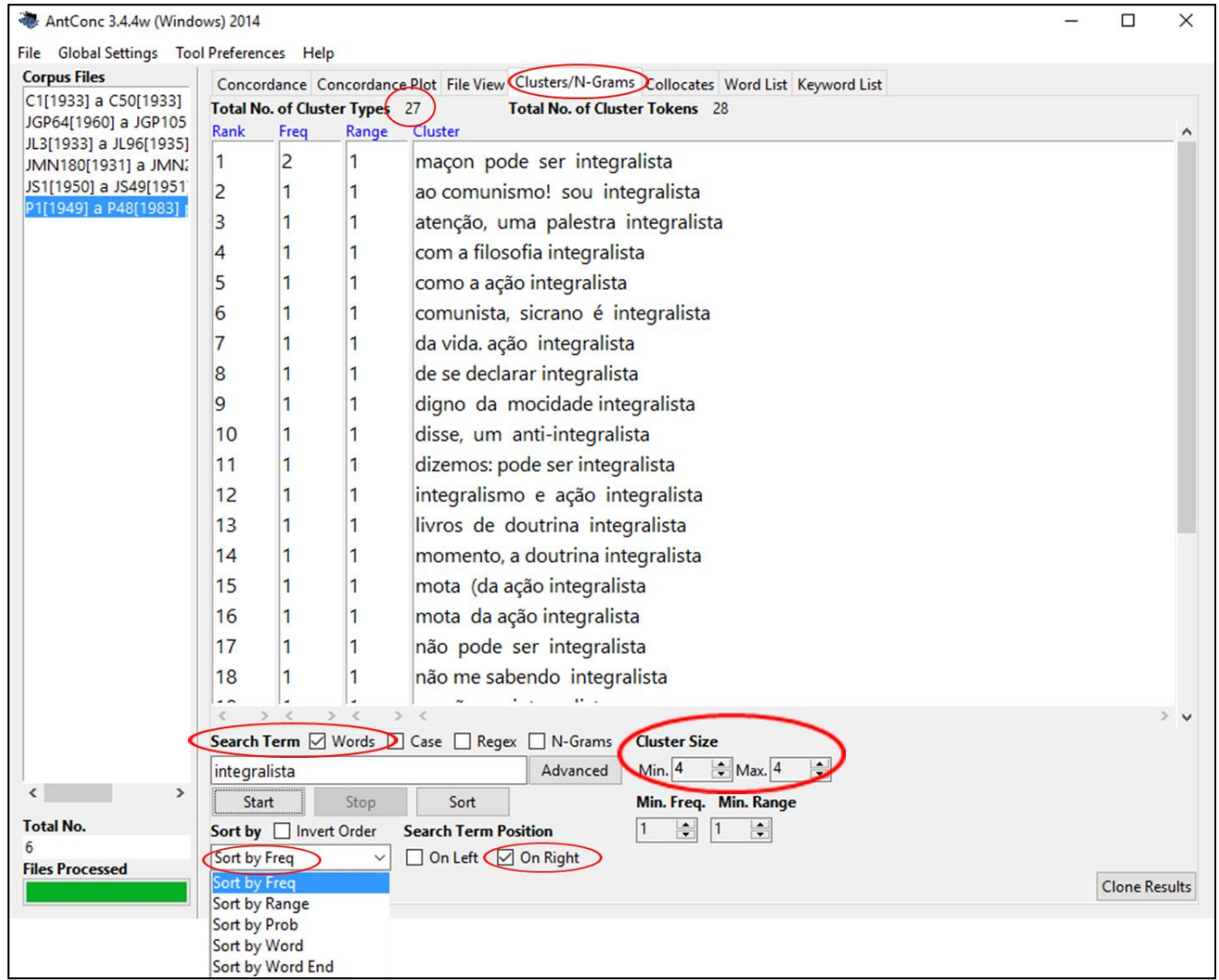

Figura 8 - Resultado da busca por <integralista > na ferramenta Clusters/N-Grams do AntConc Fonte: Elaborada pela pesquisadora.

Observa-se que a busca do Search Term foi feita por palavras, o que é o padrão. No entanto, é possível fazer por sequência de caracteres desativando a opção $W$ ords, ou por meio de uma busca sensivel a maiúsculas e minúsculas ao ativar a opção Case ou usando expressões regulares cheias (com caracteres) ativando a opção Regex. Estas opções de filtro para a busca estão disponíveis em todas as opções do AntConc.

A próxima ferramenta é Collocates. Ela permite investigar padrões não sequenciais na língua. Sua função principal é gerar listas ordenadas das palavras próximas ao termo pesquisado, chamadas de colocados. Estes são ordenados pela frequência total, pela frequência à esquerda e à direita do termo de pesquisa e pelo início e final da palavra. Também apresentam uma média estatística, gerada automaticamente pelo programa, que mede o nível de relação entre o termo pesquisado e o colocado. Além disso, pode-se 
selecionar a extensão de palavras à esquerda e à direita do termo de pesquisa para localizar os colocados e a sua frequência mínima exibida. Se, por exemplo, for necessário um intervalo de apenas uma palavra para ver as quais aparecem diretamente à direita do termo de pesquisa, é necessário marcar a opção Same, para manter o tamanho mínimo e máximo do intervalo. Nesta ferramenta, pesquisou-se pela variação <cuma > para ver as possíveis colocações que integra como base, o que se mostra nas Figuras 9 e 10.

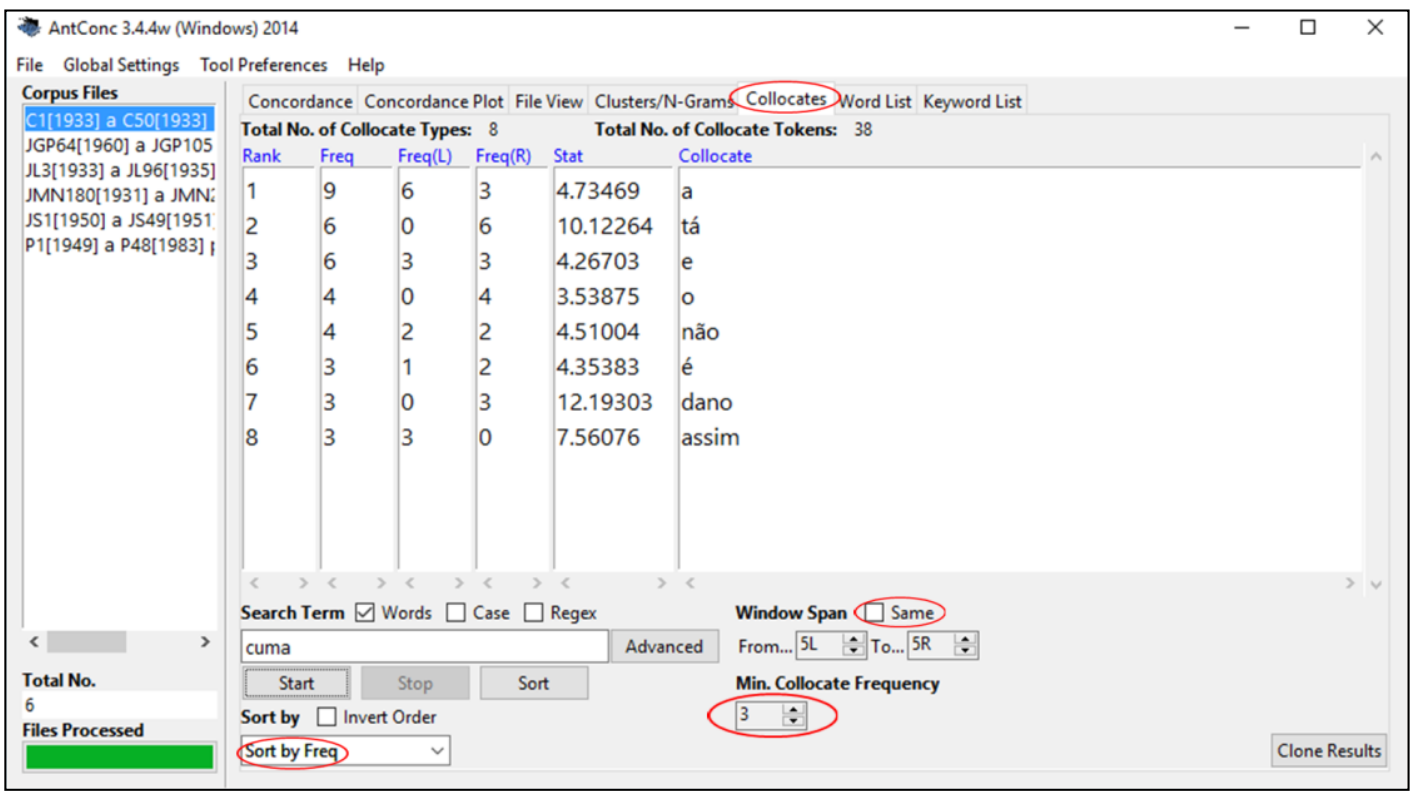

Figura 9 - Resultado da busca por <cuma $>$ na ferramenta Collocates do AntConc

Fonte: Elaborada pela pesquisadora.

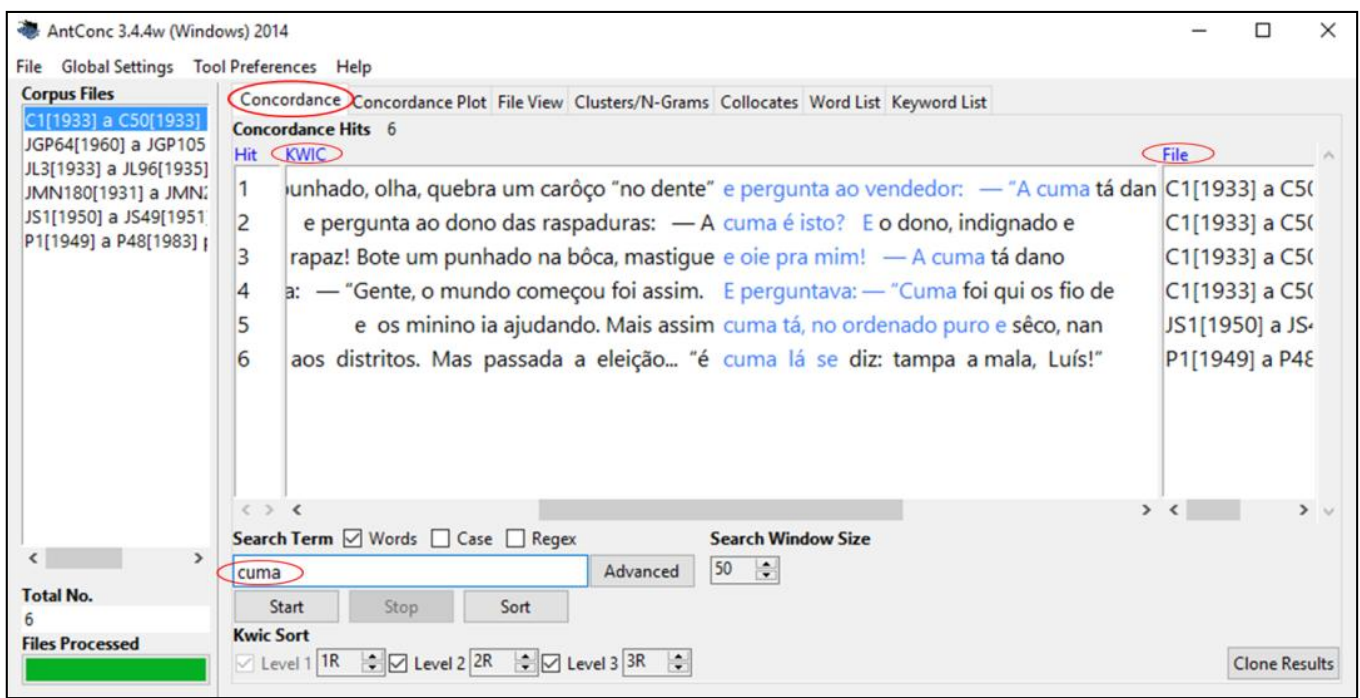

Figura 10 - Resultado da busca por <cuma $>$ na ferramenta Concordance do AntConc Fonte: Elaborada pela pesquisadora. 
Ao ativar a função Concordance visualizou-se o termo buscado nos respectivos contextos como base das colocações: "a cuma tá dano", "a cuma é isto", "cuma foi", "cuma tá" e "cuma lá se diz". Na coluna File, tem-se a identificação da localização no corpus. Neste caso, as ocorrências foram encontradas nos causos, no panfleto e no jornal O Serrinhense.

Por fim, as ferramentas Word List (lista de palavras) e Keyword List (listas de palavraschave). A Word List, gera uma lista, ou em ordem alfabética ou por frequência, de todas as palavras que constam nos arquivos selecionados para a análise linguística. Assim, é possível encontrar rapidamente quais palavras são as mais frequentes e quais são as com menor ocorrência em um corpus, neste caso, deve-se assinalar a caixa Invert Order.

A Figura 11, mostra a lista de palavras gerada pelo AntConc, que possui três colunas: 1) Rank - indica a classificação das palavras do corpus por ordem de frequência; 2) Freq mostra a frequência com que cada palavra ocorre no corpus; e 3) Word - mostra cada palavra referente aos itens das duas colunas anteriores. A lista é organizada conforme o critério escolhido dentre os três disponíveis: 1) Sort by Freq - é uma busca padrão do programa que gera uma lista de palavras por critério de frequência (cf. Figura 12); 2) Sort by Word - organiza as palavras por ordem alfabética; e 3) Sort by Word End - ordena as palavras segundo suas terminações (sílaba final). Após selecionar a opção, é só clicar em Start.

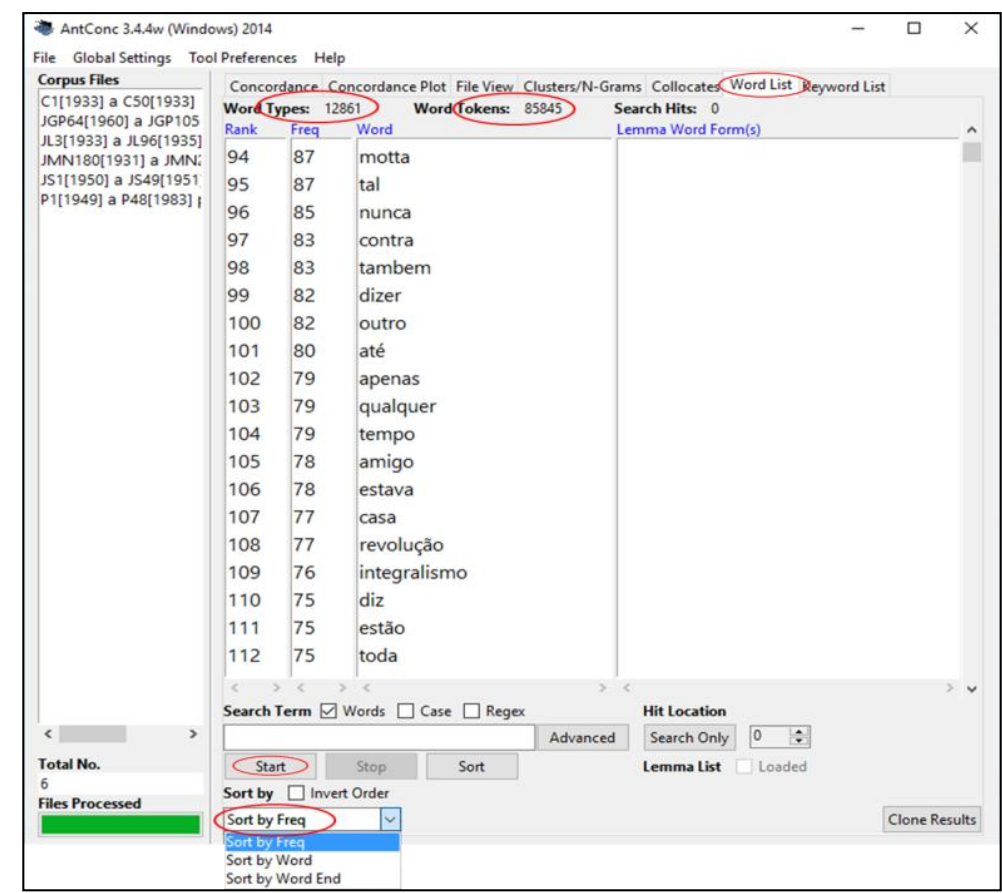

Figura 11 - Resultado da busca por critério de frequência com a ferramenta Word List do AntConc

Fonte: Elaborada pela pesquisadora. 
Como o critério de frequência não foi priorizado para eleger as entradas dos verbetes do Vocabulário de Eulálio Motta, adotou-se o critério Sort by Word para gerar uma lista de palavras em ordem alfabética. A lista compreende 12.861 tipos de palavras, que abarcam as classes abertas (substantivos, verbos, adjetivos e advérbios) e as classes fechadas (artigos, pronomes, numerais, conjunções etc.), registradas no corpus analisado.

A Keyword List, por sua vez, gera uma lista de palavras-chave, comparando a frequência das palavras raras do arquivo em análise com a frequência das palavras do corpus de referência, o que permite identificar palavras características no corpus de estudo como parte de um gênero ou de uma variedade linguística.

Para criar uma lista de palavras-chave, primeiro é preciso definir um corpus de referência. Optou-se pelo Novo Diccionário da Língua Portuguesa, de Cândido de Figueiredo, por conta do período em que foi publicado (1913) e por estar disponível online no formato $\mathrm{PDF}^{4}$. Para inserção do corpus de referência, destaca-se, na Figura 12, a ordem das ações com a indicação numérica em vermelho.

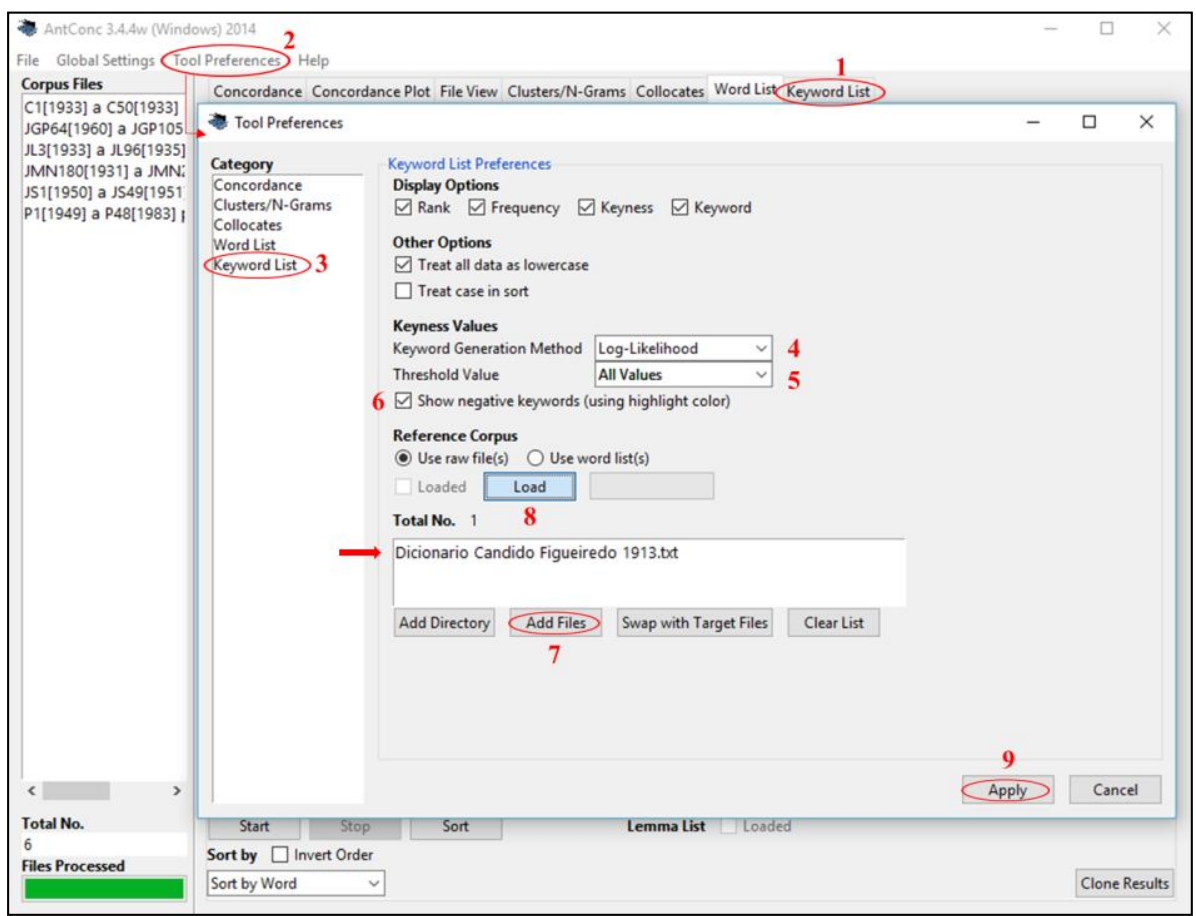

Figura 12 - Inserção do corpus de referência na ferramenta Keyword List do AntConc Fonte: Elaborada pela pesquisadora.

O primeiro passo é acessar o menu Keyword List (1), em seguida, o Tool Preferences (2) e a opção Keyword List (3). É preciso configurar o método de geração de palavras-chave, ou seja, a medida estatística para calcular a chavicidade das palavras do arquivo de destino

${ }^{4}$ Disponível em: <http://dicionario-aberto.net/dict.pdf>. Acesso em: 6 abr. 2017. 
(4). A configuração padrão recomendada é Log Likelihood (log de probabilidade). Depois, escolhe-se um limite para exibição do número de palavras-chave (5) com opções de 100 a 1000, mas o ideal é All Values (todos os valores), pois, assim, abarcar todas as ocorrências. É possível escolher se se deseja ou não exibir as palavras-chave negativas (6), que são as palavras do arquivo em análise com uma frequência baixa em comparação com a frequência no corpus de referência. Neste caso, é interessante assinalar a opção, pois evidencia as marcas de uso no corpus de análise. Para adicionar o arquivo com o corpus de referência em TXT, seleciona-se a opção Add Files (7) e, em seguida, clica-se em Load (8) para carregar. Quando se conclui o carregamento do arquivo, clica-se em Apply (9) e o programa voltará para a tela inicial em Keyword List. Para que o programa processe a lista de palavras-chave do corpus em análise, é necessário configurar o campo Sort by. Dessa forma, ajusta-se a opção de organização da lista, que pode ser: por frequência, por chave, por ordem alfabética ou por palavra-chave final. Optou-se pela Sort by Keyword, que gera a lista de palavras-chave em ordem alfabética para confrontar com a Word List também gerada em ordem alfabética. Basta clicar em Starte automaticamente a lista é gerada, como demonstrado na Figura 13.

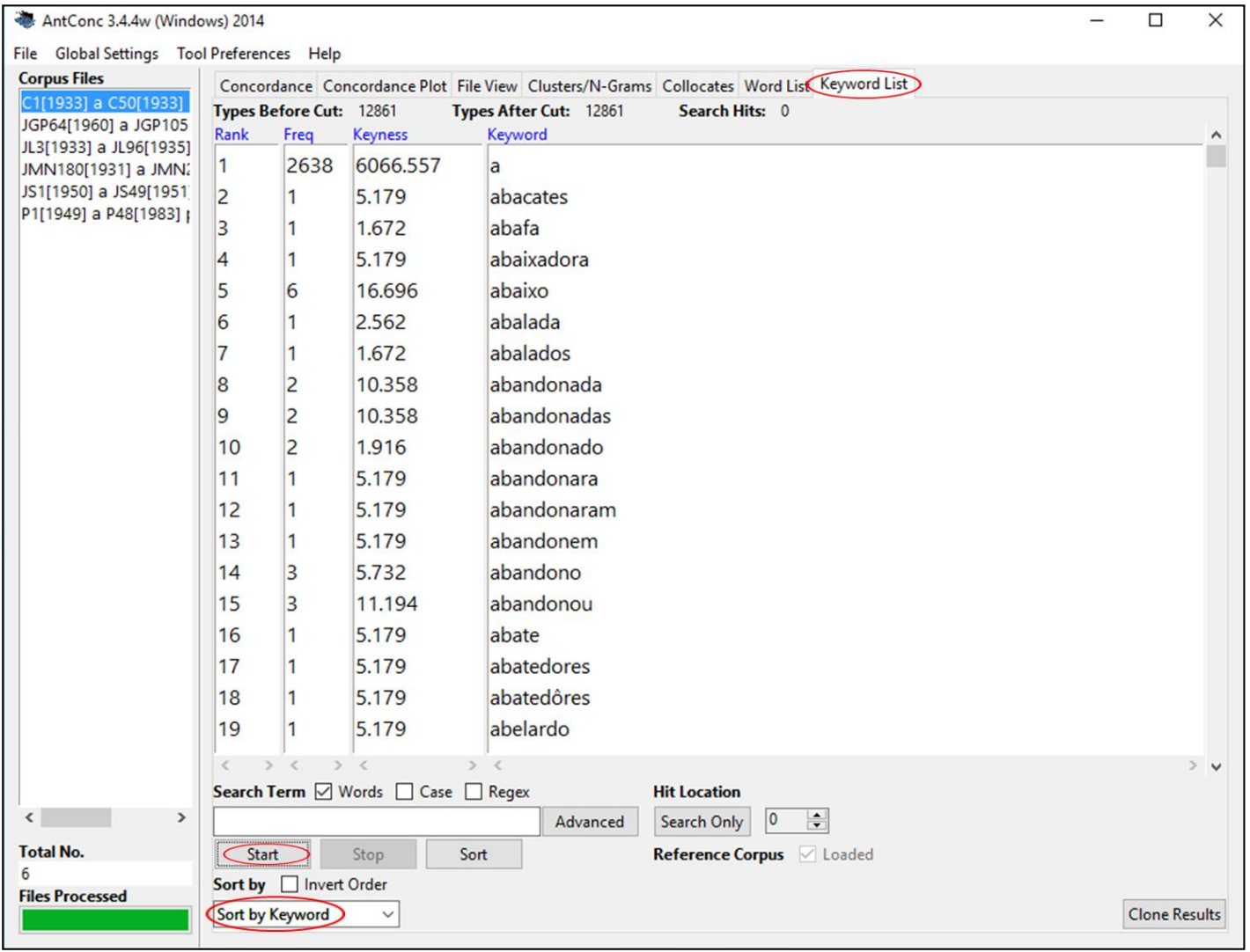

Figura 13 - Resultado da lista de palavras-chave gerada com a ferramenta Keyword List do AntConc

Fonte: Elaborada pela pesquisadora. 
Para salvar os resultados, basta acessar o menu File e selecionar a opção Save Output to Text File. Para realizar uma nova pesquisa, utilizando o mesmo corpus, limpam-se as informações anteriores, com a opção Clear All Tools and Files no menu File. Vale ressaltar que o programa não diferencia palavras empregadas com mais de um sentido, contabilizando apenas a forma gráfica.

As palavras-chave negativas, ou seja, as de baixa frequência, são exibidas na mesma lista, ao final, destacadas em azul. A contagem é reiniciada com elas. Assim, com o corpus de Eulálio Motta foi gerada uma lista de 351 palavras de baixa frequência, como na Figura 14.

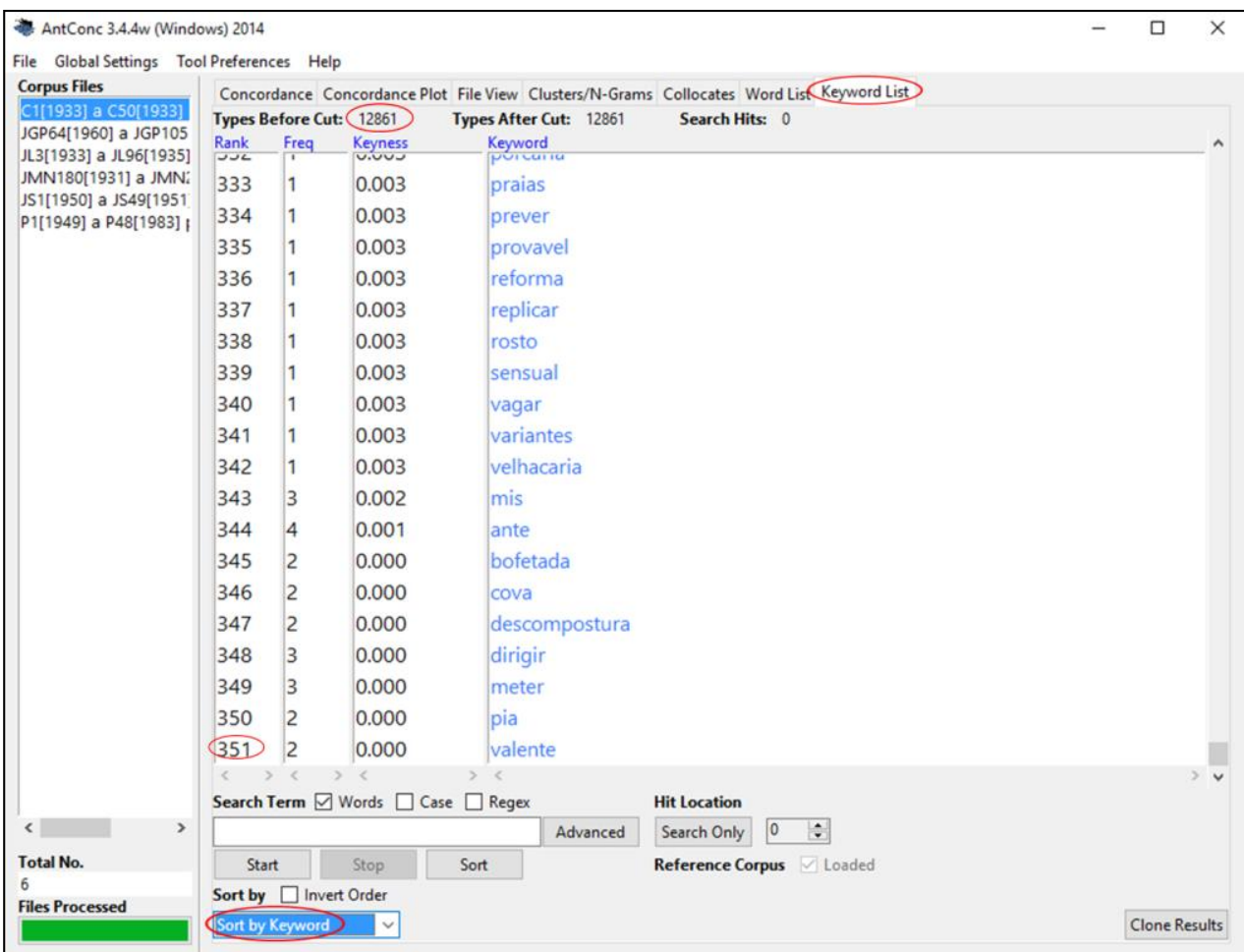

Figura 14 - Resultado da lista de palavras-chave de baixa frequência gerada com a ferramenta Keyword List do AntConc

Fonte: Elaborada pela pesquisadora.

$\mathrm{O}$ uso do AntConc mostra-se eficiente porque dimensiona o volume de dados do corpus em análise, observando-se as ocorrências e as variações de uso da língua. Ele permite explorar o corpus em sua totalidade de maneira rápida e eficiente, o que seria muito difícil manualmente. Os resultados obtidos com as listas de palavras são de extrema importância para o próximo passo, que é gerar o Vocabulário de Eulálio Motta, pois subsidiarão a escolha das entradas que irão compor a microestrutura do vocabulário.

Para a estruturação do vocabulário, utilizou-se a ferramenta Fieldworks Language Explorer (FLEx) que será descrita a seguir. 


\section{FIELDWORKS LANGUAGE EXPLORER (FLEX) E A ORGANIZAÇÃO DO CORPUS}

O FieldWorks Language Explorer (FLEx) é um programa gratuito produzido pela SIL - Sociedade Internacional de Linguística. A SIL é uma organização científica sem fins lucrativos, que tem como objetivo principal estudar e documentar línguas minoritárias para traduzir a Bíblia. Para isto, ela desenvolve e disponibiliza diversos softwares que auxiliam nas atividades de pesquisa linguística e cultural, alfabetização e educação em língua materna, elaboração de dicionários, tradução comunitária e assistida por computador e produção de mídia vernácula. A SIL foi iniciada em 1934, nos Estados Unidos, como um treinamento para missionários. Atualmente, tem mais de 6.000 membros, em mais de 50 países, e possui status consultivo formal da UNESCO e das Nações Unidas 5 .

Entre os softwares disponibilizados pela SIL, o FLEx $x^{6}$ (bomepage ilustrada na Figura 15) se destaca por ser um banco de dados que foi projetado para auxiliar os linguistas de campo a executar muitas tarefas relacionadas à documentação e à análise da língua em um único programa, como: coletar e registrar informações lexicais, fonológicas, morfossintáticas e antropocultural, interlinearizar textos, criar e publicar dicionários.

Diante das suas possibilidades, o FLEx tornou-se útil para a lexicografia, pois ele se adequa às especificidades de cada trabalho, permitindo ao lexicógrafo realizar um banco de dados mais completo com as opções de inserir textos, sons e imagens, exportar os dados em PDF e disponibiliza-los online.

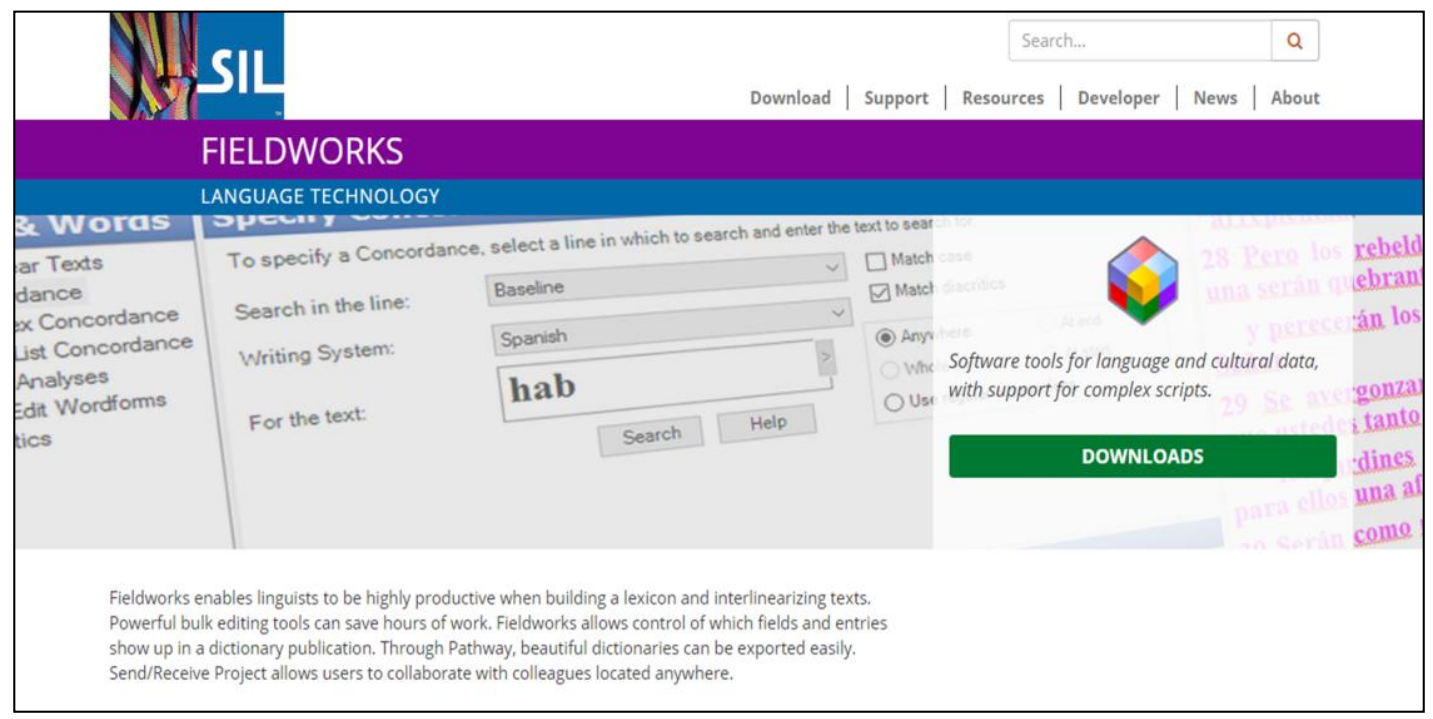

Figura 15 - Homepage do FieldWorks Language Explorer (FLEx)

Fonte: SIL - International Society of Linguisticas.

${ }^{5}$ Dados obtidos na homepage da SIL, disponível em: <https://www.sil.org/about/discover>. Acesso em: 14 abr. 2017.

${ }^{6}$ Download disponível em: <http://software.sil.org/fieldworks/download/>. Acesso em: 14 abr. 2017. 
O FLEx é livre para usar, modificar e redistribuir, de acordo com os termos da licença pública geral - GNU Lesser General Public License ${ }^{7}$. Ele está sendo constantemente aprimorado. Em 2017, o FLEx foi atualizado nos meses de janeiro, março e abril. Esta atualização é feita automaticamente e o usuário não precisa fazer backup, desde a versão FieldWorks 8. No site Github $^{8}$, é possível acompanhar como os desenvolvedores desse programa trabalham as suas versões. O Github é uma plataforma colaborativa de gerenciamento de hospedagem e criação de softwares, que permite aos usuários do mundo todo ter acesso, analisar e contribuir com o código das ferramentas. Assim, por meio da página do FLEx no Github, sugerem-se melhorias e correções, visto que a quantidade de contribuições é infinita.

Com o objetivo de analisar a produtividade e a difusão dessa ferramenta, realizouse uma consulta do FLEx no Github, como se vê na Figura 16, em março de 2017. Verificou-se no menu Commits (1), que foram enviadas e aprovadas 2.098 alterações desde a sua criação, sendo que, um mês depois, com a publicação da versão FieldWorkes 8.3.7 RC2, esse número de participações já estava em 4.384. Essa dinâmica de uso é positiva, pois facilita que falhas sejam encontradas e corrigidas mais rapidamente, além de acréscimos de novas funcionalidades, fazendo com que o programa esteja em constante melhoria e atualização.

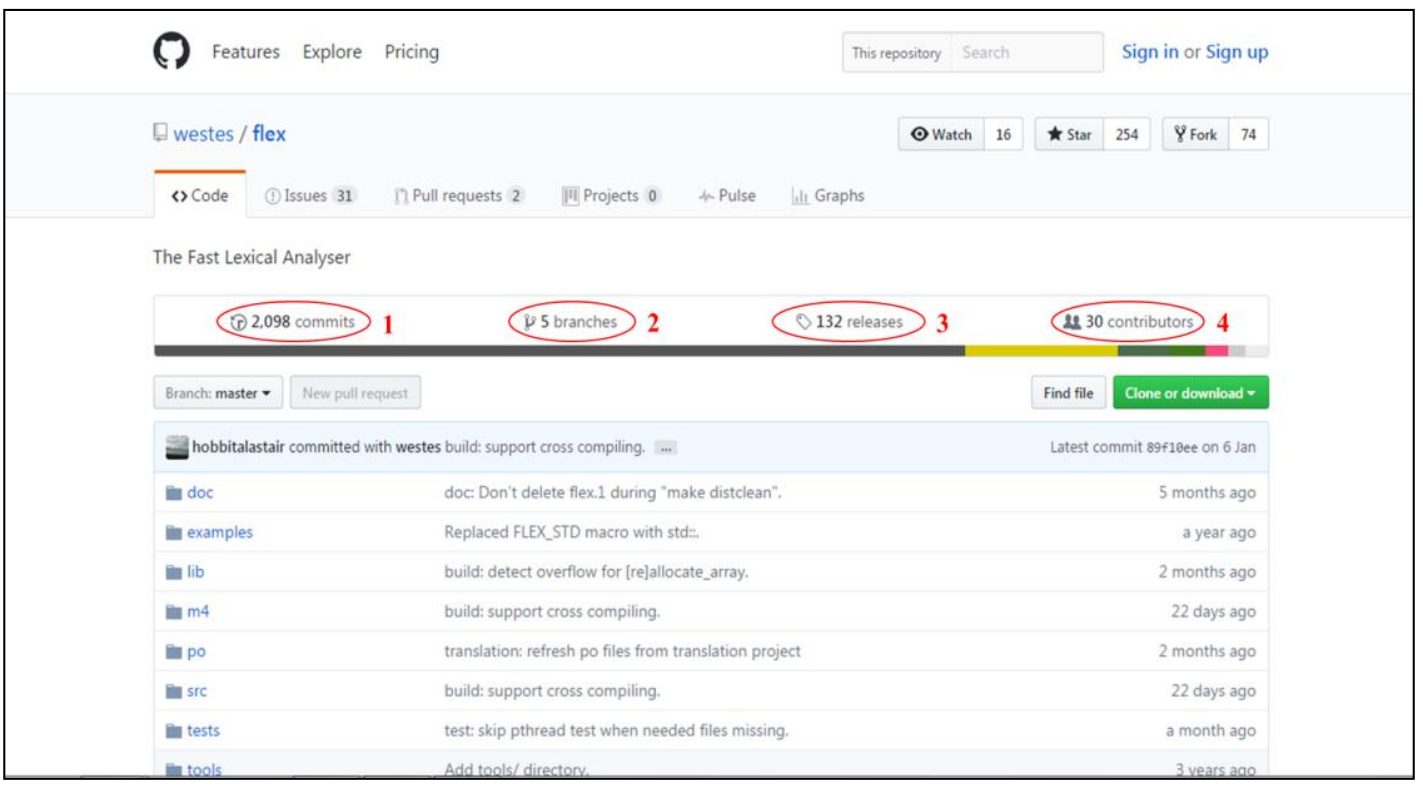

Figura 16 - Homepage do Github/FieldWorks

Fonte: Github.

Ainda, na Figura 16, no menu principal do Github, em branches (2), encontram-se disponíveis as cinco árvores utilizadas na divisão do algoritmo da ferramenta. Em releases

\footnotetext{
${ }^{7}$ Disponível em: <http://www.gnu.org/licenses/lgpl-2.1.html>. Acesso em: 23 abr. 2017.

${ }^{8}$ Disponível em: <https://github.com/sillsdev/FieldWorks>. Acesso em: 17 mar. 2017.
} 
(3), estão 132 versões funcionais do sistema que foram liberadas e, até o momento, são 30 colaboradores (4) que cooperam com o código.

O FLEx permite que os usuários, com acesso ao mesmo projeto, colaborem com pesquisadores localizados em qualquer lugar, por meio de um processo de sincronização dos dados. Logo, várias pessoas podem participar do mesmo projeto, otimizando o tempo e aumentando a produtividade.

Por todas as possibilidades e vantagens destacadas, adotou-se a versão FieldWorks 8.3.7 RC2, atualizada em 6 de abril de 2017, para a realização do Vocabulário de Eulálio Motta. Vale ressaltar que este projeto foi cadastrado na plataforma da SIL e está registrado no repositório Language Depot ${ }^{9}$, para que seja possível futuramente sincronizar todos os dados obtidos e assim poder ampliar o corpus de análise e a equipe de trabalho.

A seguir, descreve-se a estrutura e o funcionamento do programa, a fim de demonstrar a sua aplicação. Após o download do FLEx, o primeiro passo é a criação de um novo projeto na plataforma e a definição do sistema de escrita, nesse caso, português. Em seguida, o FLEx remete o usuário para a tela inicial, como se demonstra na Figura 17.

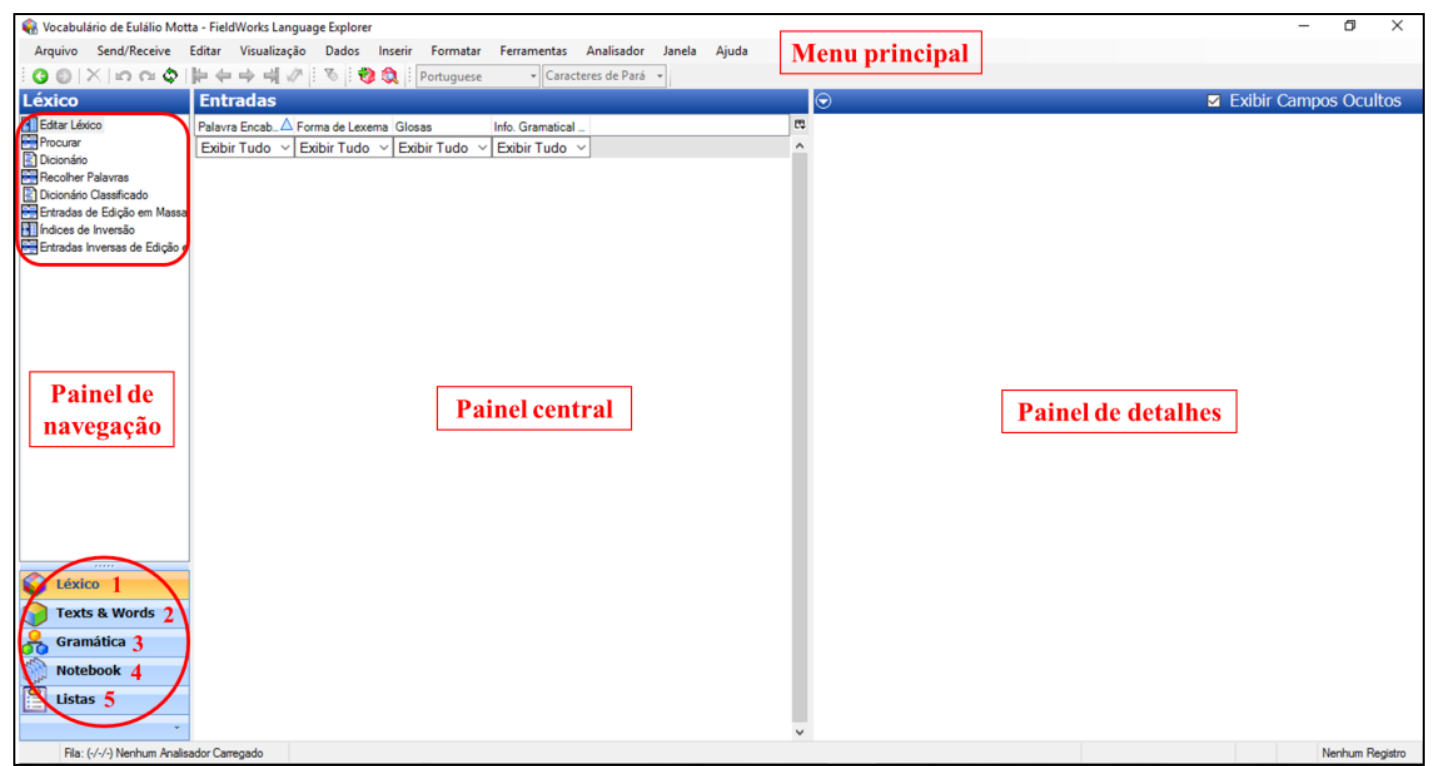

Figura 17 - Tela inicial do FLEx

Fonte: Elaborada pela pesquisadora.

Além da barra do menu principal, que navega pelas funções mais gerais do FLEx, como abrir ou restaurar um projeto, a janela do programa é dividida em três painéis principais. À esquerda, o painel de navegação, apresenta uma lista, no canto inferior, com as cinco áreas de trabalho - Léxico, Texts \& Words, Gramática, Notebook e Listas ${ }^{10}$. Cada

\footnotetext{
${ }_{9}$ Disponível em: <https://public.languagedepot.org/projects/show/br-por-flex?jump $=$ my $>$. Acesso em: 28 fev. 2017.

${ }^{10}$ O FLEx é originalmente em língua inglesa, por isso, quando se define o sistema de escrita em português, nem todos os campos são traduzidos.
} 
uma tem as suas opções específicas, elencadas no canto superior. No centro, o painel central, e à direita, o painel de detalhes, ambos exibem o campo de edição da ferramenta selecionada à esquerda.

As cinco áreas de trabalho assinaladas na Figura 17 têm as seguintes finalidades: Léxico (1) é o espaço onde se constroem os verbetes. Possui campos pré-definidos, que podem ser visualizados ou ocultados de acordo com a configuração adotada. Texts \& Words (2) é o local onde são armazenados todos os textos transcritos. Gramática (3) é o recurso que permite inserir a classificação gramatical das unidades lexicais armazenadas. Notebook (4) exibe todos os dados antropológicos registrados, sendo possível acrescentar informações. Nas versões anteriores do FLEx, essa função era desenvolvida por outro programa. Por fim, Listas (5) permite a edição de opções de lista para determinados campos no banco de dados, gerada a partir dos dados inseridos durante a configuração do produto.

Para iniciar a construção do Vocabulário de Eulálio de Motta na plataforma do FLEx foi necessário inserir o corpus da pesquisa na área Texts \& Words, como se mostra na Figura 18, na subseção Textos Interlinearizados (1), pelo atalho ou em Inserir no menu principal (2).

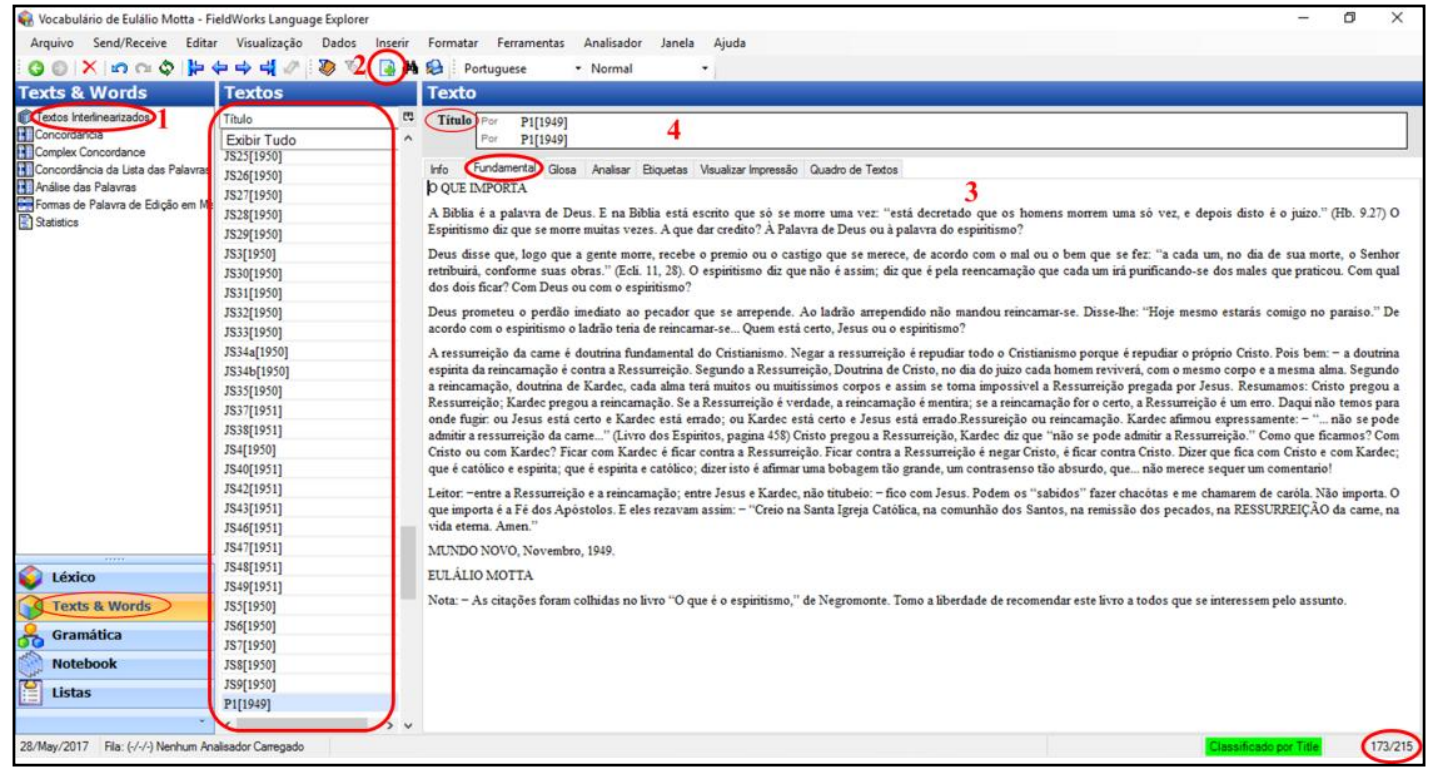

Figura 18 - Inserção do corpus da pesquisa na área Texts \& Words do FLEx Fonte: Elaborada pela pesquisadora.

Uma vez fixados na aba Fundamental (3), do terceiro painel, o corpus já está salvo. O título pode ser inserido na aba específica (4) ou em Info, onde se tem os campos para registrar todos os metadados do texto (fonte, gênero, comentários, participantes, localização e dados da coleta). A data de criação e de modificação dos dados são atualizadas automaticamente. Os metadados dos 215 textos que compõem o corpus desta análise foram editados individualmente, como se vê na Figura 19. 


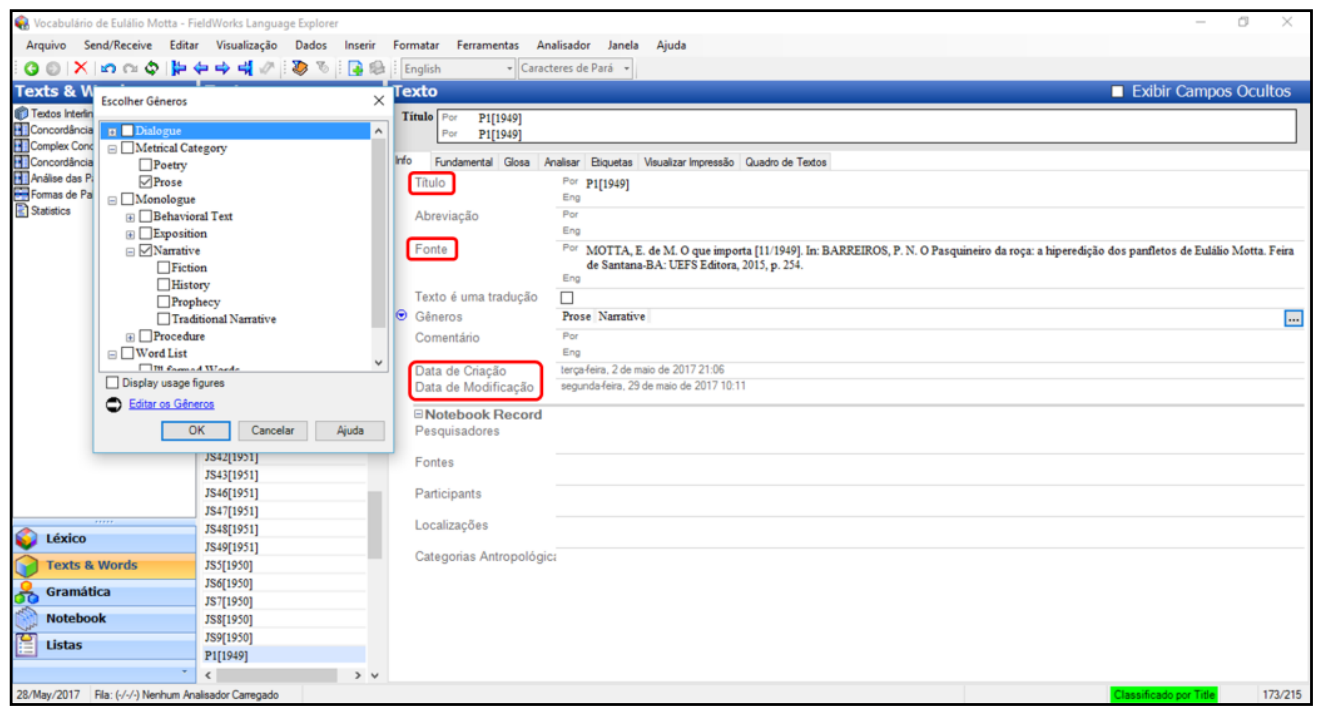

Figura 19 - Edição dos metadados do corpus da pesquisa na área Texts \& Words do FLEx Fonte: Elaborada pela pesquisadora.

Ainda nessa área de trabalho, Texts \& Words, é possível editar, extrair a concordância da lista de palavras dos textos conforme sua ocorrência, fazer diversos tipos de buscas e ter acesso à estatística geral. Após a inserção do corpus, iniciou-se a criação das entradas lexicais, as quais foram escolhidas a partir de uma pré-seleção da Word List gerada pelo AntConc. O FLEx possibilita adicionar entradas de quatro maneiras diferentes. Para a organização do Vocabulário de Eulálio Motta, elegeram-se duas opções que mais se adequaram à proposta deste trabalho em compor um vocabulário de lexias simples, compostas e complexas. A primeira forma de registro das entradas adotada foi pela área de trabalho Léxico, como se demonstra na Figura 20. Editar léxico é a principal ferramenta de edição do FLEx, pois permite registrar várias informações para cada entrada lexical.

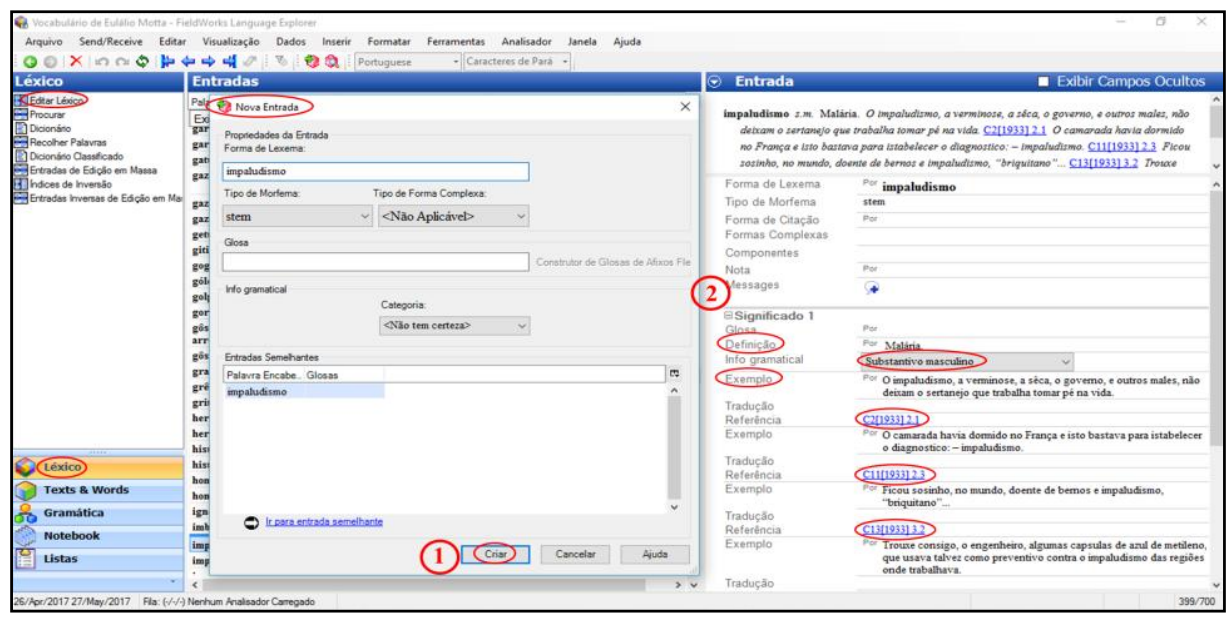

Figura 20 - Adição de nova entrada na área Léxico do FLEx Fonte: Elaborada pela pesquisadora. 
Após adicionar a nova entrada no painel central, o programa abre uma tela no painel de detalhes, onde é possível inserir a definição, a classificação gramatical, as variantes (quando houver), as abonações, além de som e imagem para ilustrar a entrada lexical. A busca pelos exemplos no corpus pode ser feita automaticamente, sendo a referência gerada a partir do código do arquivo pré-estabelecido na edição dos metadados. Tudo é feito com a aprovação do usuário, sendo possível fazer alterações.

A segunda forma adotada para acrescentar as entradas ao Vocabulário de Eulálio Motta foi pela aba Glosa em Texts \& Words, como se vê na Figura 21. Nela, o corpus é fragmentado e numerado por sentença, abrindo uma caixa de diálogo que permite definir todos os itens lexicais, juntamente com a classificação gramatical, e adicioná-las como entrada. Além disso, é possível incluir mais de uma acepção para a mesma entrada ou criar entradas diferentes para as palavras homógrafas.

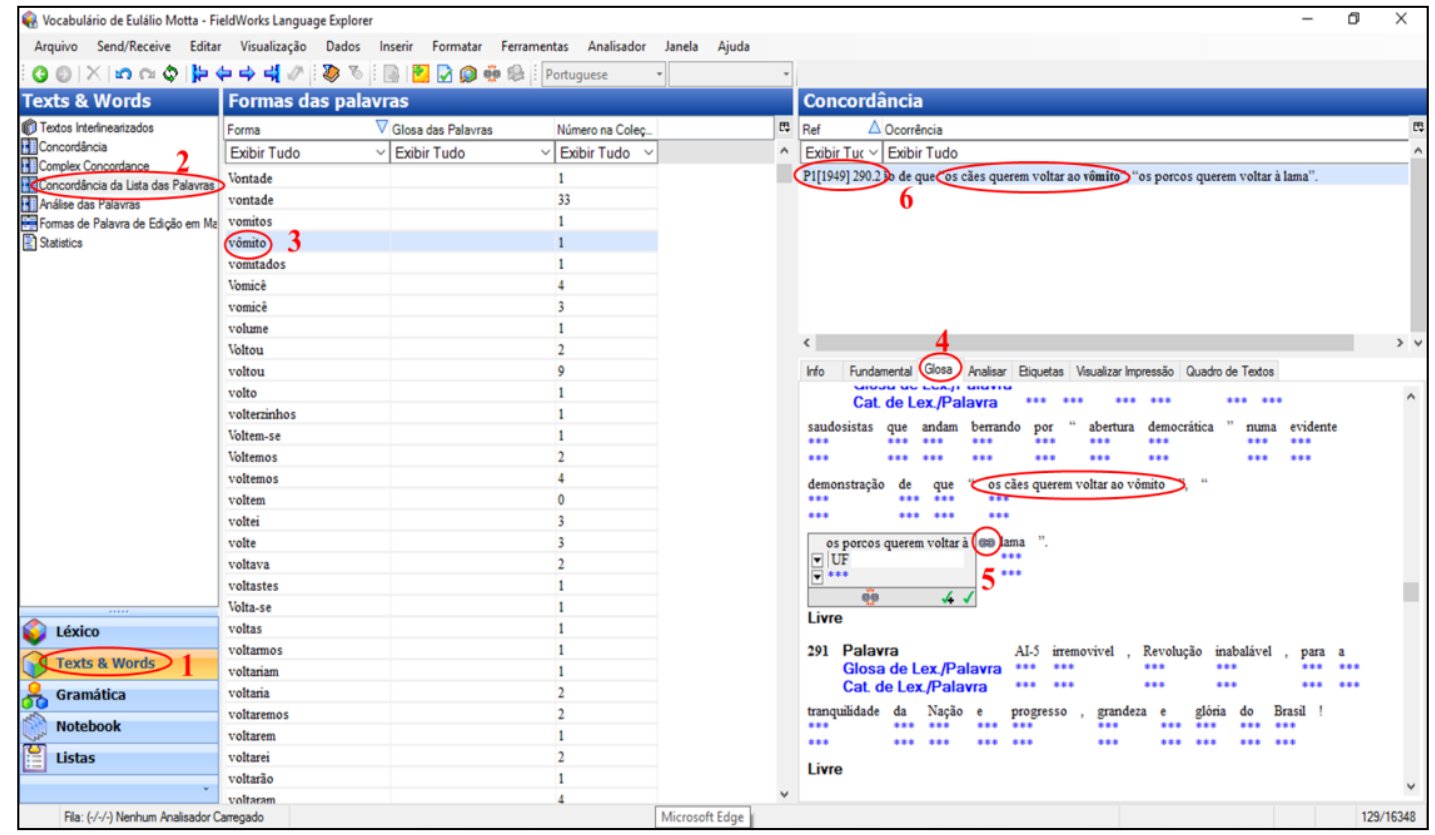

Figura 21 - Seleção e adição de nova entrada na área Texts \& Words do FLEx Fonte: Elaborada pela pesquisadora.

No painel central, visualizam-se todas as formas de palavras encontradas no corpus com o respectivo número de ocorrências. Além da praticidade em poder escolher o lema diretamente do texto, essa aba dispõe de um link que permite unir as palavras. Esta função é imprescindível para elencar as entradas de lexias compostas e complexas.

$\mathrm{Na}$ área Gramática, ajustou-se, de acordo com as demandas do corpus, o modelo de classificação proposto pelo programa. Nesse sentido, diferenciaram-se substantivos masculinos (s.m.) de femininos (s.f.) e os verbos transitivos (v.t.) dos intransitivos (v.i.). Acrescentaram-se também advérbios (adv.), adjetivos (adj.) e unidades fraseológicas (UF). Em Listas, traduziu-se a classificação dos tipos de variantes para que pudessem ser registradas no vocabulário. 
Finalizada a edição das entradas do vocabulário, a visualização do trabalho fica disponível na área Léxico, na aba Dicionário (cf. Figura 22). Em Ferramentas, no menu principal, o usuário pode configurar o que e como será exibido. O FLEx organiza o trabalho lexicográfico em formato PDF e possibilita a impressão. Basta acessar a opção Imprimir na aba Arquivo, como se observa na Figura 22:

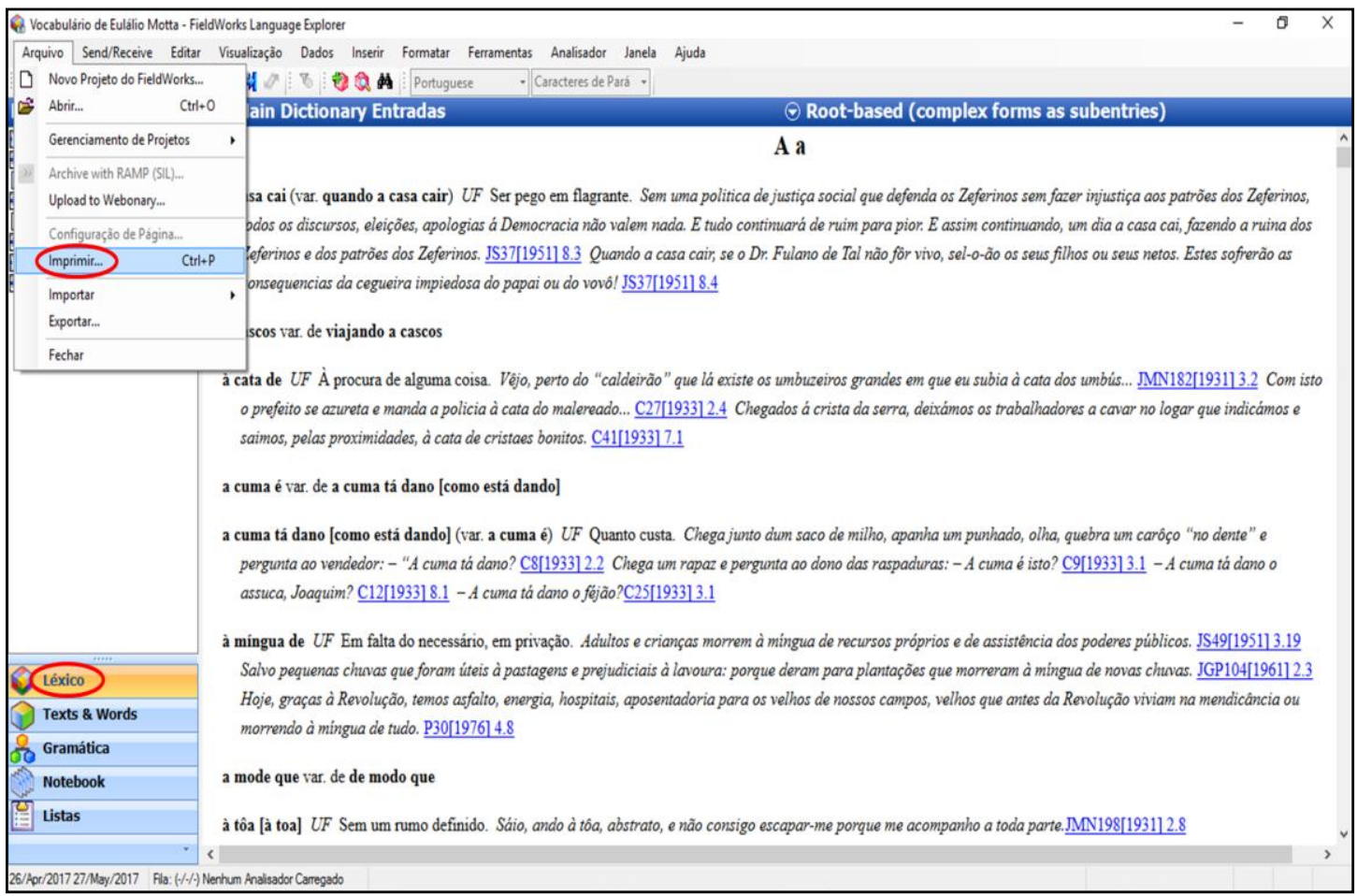

Figura 22 - Janela de impressão do FLEx

Fonte: Elaborada pela pesquisadora.

É possível, também, exportar o trabalho final para outros programas que fazem a edição em formato de dicionário e possibilitam disponibilizar online. Para o Vocabulário de Eulálio Motta, optou-se por exportá-lo para o programa Pathway ${ }^{11}$, que é integrado a interface da SIL FieldWorks. O Patway gera o arquivo editável e transfere para o LibreOffice Writer, onde é possível alterar a formatação do estilo de dicionário padrão, como se vê na Figura 23.

11 Pathway disponível em: <http://pathway.sil.org/>. Acesso em: 29 maio 2017. 


\section{A a}

a casa cai (var. quando a casa cair) UF Ser pego em flagrante. Sem uma politica de fustiça social que defenda os Zeferinos sem fazer injustiça aos patrōes dos Zeferinos, todos os discursos, eleiçôes, apologias á Democracia năo valem nada $E$ tudo continuará de rutm para pior. $E$ assim continuando, um dia a casa cai, fazendo a ruina dos Zeferinos e dos patrồes dos Zeferinos. JS37[1951] 8.3 Quando a casa catr, se o Dr. Fulano de Tal não fôr vivo, sel-a-ầ os seus fllhos ou seus netos. Estes sofrerão as consequencias da ceguetra impledosa do papai ou do vovó! JS37[1951] 8.4

a cascos UF Longa caminhada de animais de um municipio a outro para ser abatido. $E$ principalmente: as botadas gordas de Mundo Novo, Rut Barbosa, Monte Alegre, Macafuba enfom de toda esta zona de intensa produção; boladas que continuam viajando a cascos para o abate em Sahador: P16[1971] 4.4 A cascos, perdendo centenas de arrobes em cada boiadal $A$ cascos, como na era dos carros de boist $A$ cascos, nesta era do asfalto! P16[1971] 5.1 "As boiadas seriam transportadas como as de Minas, em poucas horas envez de muitos dias, em veiculos modernos envez de penosas, longas e tristes caminhadas a cascos. P16[1971]8.2

à cata de UF A procura de alguma coisa. Véjo,
Joaquim? C12[1933] 8.1 - A cuma tá dano o fejdo? C25[1933] 3.1

à mingua de UF Em falta do necessário, em privação. Adultos e crianças morrem à mingua de recursos próprios $e$ de assisténcia dos poderes puiblicos. JS49[1951] 3.19 Salvo pequenas chwas que foram úteis $\grave{a}$ pastagens e prejudiciais $\grave{a}$ lavoura: porque deram para plantações que morreram à mingua de novas churvas. JGP104[1961] 2.3 Hoje, graças à Revolução, temos esfaito, energia, hospitais, aposentadoria para os velhos de nossos campos, velhos que antes da Revoluçäo viviam na mendicancia ou morrendo à mingua de tudo. p30[1976] 4.8

a mode que var. de de modo que

à tôa [à toa] $U F$ Sem um rumo definido. Sáio, ando à tóa abstrato, e não consigo escapar-me porque me acompanho a toda parte. JMN198[1931] 2.8

abafa a banca [abafar a banca] UF Ser vitorioso $\mathrm{em}$ qualquer empreitada. Volta-se a verificar que a raça incubrastl é o grande coringa do mudo bovino. Como qualquer raça o mestiço de indubrasil abafa a banca. P37[1978]4.5

abaixadora s.f. Subestação de energia. Roberto Santos, corresponda a esta vitória da Arena

Figura 23 - Exemplo do Vocabulário de Eulálio Motta

Fonte: Elaborada pela pesquisadora.

\section{CONSIDERAÇÕES FINAIS}

O Vocabulário de Eulálio Motta busca ser representativo de um universo de discurso (BARBOSA, 2001) de Eulálio Motta e visa como produto final "uma lista exaustiva das ocorrências que figuram num corpus" (DUBOIS et al., 1993 [1978], p. 613). Classifica-se, de acordo com os critérios de Haensch (1982), como um estudo de caráter linguístico, pois define palavras designativas (voltadas a referentes extralinguísticos), além de registrar a classe gramatical e o gênero das unidades lexicais lematizadas. Baseia-se no sistema linguístico individual de um autor, sendo todos os exemplos extraídos dos textos-fonte de estudo, que se configuram como abonações. É uma obra de constituição monolíngue por contemplar apenas unidades léxicas da língua portuguesa. Apresenta uma seleção lexical parcial e seletiva, pois registra uma parcela do léxico da língua, sincrônica e de caráter descritivo, que permite identificar as marcas de uso diafásica (pela riqueza da linguagem formal e informal utilizada), diastrática (por permitir o acesso a um vocabulário específico de uma comunidade linguística pouco documentada) e diatópica (por traduzir 
os valores e as crenças do povo sertanejo de uma determinada região). As entradas foram ordenadas semasiologicamente, em ordem alfabética, partindo dos significantes para os significados.

O trabalho lexicográfico empreendido evidenciou as marcas linguísticas do escritor Eulálio Motta e de seu entorno sociocultural. A seleção lexical empreendida por ele, na elaboração de seus textos, retrata a sua visão de mundo, a sua formação intelectual, ao mesmo tempo em que documenta a cultura e a história de um grupo social em uma determinada época. As unidades lexicais que compõem a macroestrutura do Vocabulário de Eulálio Motta remetem às histórias locais, expressões populares, crenças, festas populares, a questões políticas, sociais e religiosas, ao cotidiano do homem sertanejo do município de Mundo Novo e regiões circunvizinhas.

Como resultado principal, obteve-se o Vocabulário de Eulálio Motta, composto por 700 entradas, que foram classificadas em: substantivo feminino, substantivo masculino, verbo transitivo, verbo intransitivo, adjetivo, advérbio e unidade fraseológica (BARREIROS; TELLES, 2017), sendo 505 lexias simples, 61 lexias compostas e 134 lexias complexas.

Este trabalho teve por finalidade contribuir para a preservação de costumes e valores culturais do homem sertanejo, expresso no seu uso da língua, e corroborar a importância de se preservar, através de textos literários, a cultura, a língua e a história local do povo sertanejo do Semiárido Baiano. A partir dos dados obtidos, vários aspectos podem ser explorados em futuras pesquisas, relacionadas à formação histórica da Língua Portuguesa e à variação linguística.

\section{REFERÊNCIAS}

ANTHONY, Laurence. AntConc (Versão 3.4.3) [Software de Computador]. Tóquio, Japão: Universidade de Waseda. 2014. Disponível em: <http://www.laurenceanthony.net/>. Acesso em: 16 fev. 2017.

BARBOSA, Maria Aparecida. Dicionário, vocabulário, glossário: concepções. In: ALVES, Ieda Maria. (Org.). A constituição da normaliz̧ação terminológica no Brasil. 2. ed. São Paulo: FFLCH/CITRAT, 2001, p. 23-45.

BARREIROS, Liliane L. S. O vocabulário de Eulálio Motta. 359f. Tese (Doutorado em Letras e Linguística) - Instituto de Letras, Universidade Federal da Bahia, Salvador, 2017.

BARREIROS, Liliane L. S. Babia Humorística: causos sertanejos de Eulálio Motta. Feira de Santana-BA: UEFS Editora, 2016.

BARREIROS, Liliane L. S.; TELLES, Célia M. As unidades fraseológicas no Vocabulário de Eulálio Motta. Revista Virtual de Estudos da Linguagem, v. 15, p. 17-36, 2017.

BARREIROS, Patrício N. O pasquineiro da roça: a hiperedição dos panfletos de Eulálio Motta. Feira de Santana-BA: UEFS Editora, 2015. 
BARREIROS, Liliane Lemos Santana; BARREIROS, Patrício Nunes. O vocabulário da Ditadura Militar nos panfletos de Eulálio Motta. Linguística e Filologia Portuguesa (USP), São Paulo, v. 17, n. 2, p. 385-420, jul./dez., 2015.

BARREIROS, Patrício Nunes. Eulálio Motta: um panfletário no sertão da Bahia. Revista do Instituto de Estudos Brasileiros, n. 67, São Paulo, p. 57-80, 2017.

BARREIROS, Patrício Nunes. Por uma abordagem da História Cultural das práticas de escrita na edição de textos. Alea: Estudos Neolatinos (Impresso), v. 19, p. 389-414, 2017.

BERBER SARDINHA, T. Linguística de Corpus. Barueri, SP: Manole, 2004.

BIDERMAN, Maria Tereza C. Teoria lingüística: teoria lexical e lingüística computacional. 2 ed. São Paulo: Martins Fontes, 2001.

BIDERMAN, Maria Tereza C. A ciência da Lexicografia. Alfa Revista de Linguística. São Paulo, n. 28 (supl.), p. 1-26, 1984.

BIDERMAN, Maria Tereza C. Teoria lingüistica: lingüística quantitativa e computacional. Rio de Janeiro: Livros Técnicos e Científicos, 1978.

BIDERMAN, M. T. C. A Categoria do Gênero (nas línguas românicas). Tese (LivreDocência). São Paulo: USP, 1974.

BIDERMAN, M. T. C. Análise Computacional de Fernando Pessoa (Ensaio de Estatística Léxica). Tese (Doutorado em Filologia e Língua Portuguesa). Faculdade de Filosofia, Letras e Ciências Humanas/USP, São Paulo, 1969.

DUBOIS, Jean et al. Dicionário de Linguística. 9. ed. Tradução de Frederico Pessoa de Barros et al. São Paulo: Cultrix, 1993 [1978].

HAENSCH, Günther. Tipología de las obras lexicográficas. In: HAENSCH, G. et al. La lexicografia: de la linguística teórica a la lexicografia práctica. Madrid: Gredos, 1982, p. 95187.

OTHERO, Gabriel de A.; MENUZZI, Sérgio de M. Linguística computacional: teoria e prática. São Paulo: Parábola, 2005.

POTTIER, Bernard. Lingüistica general: teoria y descripción. Trad. Maria Victoria Cantalina. Madrid: Gredos, 1977. 